\title{
Chronic and severe hypoxic conditions in Paracas Bay, Pisco, Peru: Consequences on scallop growth, reproduction, and survival
}

\author{
Aguirre-Velarde Arturo ${ }^{1,}{ }^{*}$, Thouzeau Gerard ${ }^{2}$, Jean Frederic ${ }^{4}$, Mendo Jaime ${ }^{3}$, Cueto-Vega Rosa ${ }^{3}$, \\ Kawazo-Delgado Midori ${ }^{3}$, Vásquez-Spencer Jazmín ${ }^{3}$, Herrera-Sanchez Diego ${ }^{3}$, \\ Vega-Espinoza Alex ${ }^{3}$, Flye-Sainte-Marie Jonathan ${ }^{4}$
}

${ }^{1}$ Laboratorio de Ecofisiología Acuática, IMARPE, Esquina Gamarra y General Valle S/N Chucuito Callao, Peru

2 LEMAR, UMR 6539 (UBO/CNRS/IRD/Ifremer), IUEM, Rue Dumont d'Urville, 29280 Plouzané, France

3 Facultad de Pesquería, Universidad Nacional Agraria La Molina, Av. La Molina S/N, La Molina, Lima, Peru

* Corresponding author : Arturo Aguirre-Velarde, email address : jah arturo@hotmail.com

\begin{abstract}
:
The response of Argopecten purpuratus (Peruvian scallop) to environmental conditions was studied in the upwelling-influenced Bay of Paracas (Peru). Scallops growth and reproduction were monitored weekly over a 7-month period under two conditions (culture depths): on the bottom and $2 \mathrm{~m}$ above (suspended culture). At the same time, a high-frequency environmental monitoring was realized at the aforementioned depths. The results indicate that environmental conditions in the Bay are highly variable, especially during the summer: temperature fluctuations up to $8 \circ \mathrm{C}$ were recorded in less than one day while oxic conditions ranged from oversaturation to anoxia. Milky-turquoise waters discoloration events (sulphide presence suspected) were simultaneously observed together with anoxic conditions and sudden temperature drops. Increased stratification and upwelling favorable winds during the summer might be partly responsible for the observed environmental variability. Higher somatic and gonadal growth were observed in scallops growing in suspended culture compare with bottom culture. This pattern might be related to different environmental conditions at culture depth: turbidity was lower in suspended culture and hypoxic conditions occurred only $18 \%$ of the whole study period versus $48 \%$ on the bottom. The Gonadosomatic index varied according to an approx. 30-day cycle between winter and late spring and it was synchronous between the different scallop size groups. During summer, when milky waters and anoxic events occurred frequently, cessation of reproduction, somatic weight losses and increased scallop mortality were observed. Exposure to severe hypoxia and related environmental conditions clearly affected scallop bioenergetics and subsequently growth and reproduction. In addition, the occurrence of milky waters harmed the survival of the Peruvian scallop in culture. These results are discussed in terms of management strategies for sustainable scallop aquaculture in the Bay.
\end{abstract}




\section{Highlights}

- High frequency environmental recording in Paracas bay (Peru) showed frequent and chronic hypoxic conditions. Exposure to severe hypoxia and related environmental conditions clearly affected scallop bioenergetics and subsequently growth and reproduction. Milky-turquoise waters events affect negatively survival of Peruvian scallop

Keywords: Argopecten purpuratus, high frequency monitoring, coastal upwelling, hypoxic/anoxic conditions, growth, reproduction, aquaculture, milky-turquoise water/aguas blancas 


\section{Introduction}

Around the world, hypoxic events have a major impact on coastal resources with negative consequences for human activities relying on them (Rabalais and Turner, 2001; Gray et al., 2002; Levin et al., 2009; Zhang et al., 2010). In the Peruvian upwelling system, natural trophic availability supports an important biomass of filter-feeding organisms (fish and invertebrates) that include cultivated bivalves. This large amount of organic matter in the ecosystem is also the cause of oxygen depletion because of degradation and remineralization processes. Consequently, the oxygen minimum zone off Peru is not so deep (Paulmier and Ruiz-Pino, 2009) which impacts, together with the high environmental variability, on the pelagic resources exploited throughout the Peruvian upwelling system (Barber and Blake, 1983; Barber and Chávez, 1986; Ñiquen and Bouchon, 2004). Although these impacts have been studied during at least the last six decades, for nearshore zones the links between the upwelling dynamics and living resources inside Peruvian coastal bays ( < 20m depth) remain poorly known. In a global change context, an increased exposition, both in intensity and frequency, of resources to environmental stressors including hypoxia is expected (Crain et al., 2008). In addition, upwelling areas are considered vulnerable and 
especially sensitive due to the ecosystem services (fishing and aquaculture) they provide (Bakun et al., 2010; Belmadani et al., 2014). The case study of Paracas Bay can help understanding the oceanographic dynamics that cause oxygen depletion and its consequences on aquaculture activities. This may help delineating strategies for sustainable aquaculture.

Paracas Bay is a traditional scallop production area under the influence of one of the most active upwelling zones of the Peruvian coast. In spite of productive advantages like relative greater growth rates and higher gonadosomatic index (GSI) than elsewhere in Peru, scallop production in Paracas Bay was historically affected by mass mortality events causing economic threat to local producers. Environmental conditions associated to these events have rarely been described (see Cabello et al., 2002). Nevertheless, oceanographic data reports available for the Pisco area (including Paracas Bay) frequently show low oxygen concentrations $<1.0 \mathrm{mg} \mathrm{L}^{-1}$, see Jacinto et al., 1996a, b; Guzmán et al., 1997; Sánchez et al., 1997; Solis Acosta, 2000; Solis Acosta and Inca, 2000), which could limit scallop production. In Paracas Bay, evidences for high fluctuations of environmental parameters (temperature, primary production and oxygen saturation) have been shown in relation to El Niño (Wolff, 1987, 1988). Sears (1954) also found strong temperature variations independently of El Niño and related it to local water heating due to the solar radiations. More recently, high frequency monitoring under neutral (normal) ENSO conditions allowed recording dramatic variations in temperature (Aguirre-Velarde et al., 2015, 2016) and dissolved oxygen concentration (Aguirre-Velarde et al., 2016). Paracas Bay is also affected by the occurrence of milky-turquoise water events, locally known as "aguas blancas", that producers related with increased scallop mortality. Elemental sulphur microgranules originating from sulphide oxidation would cause these characteristic discolorations (Ohde et al., 2007). Such water discolorations have also been described in Namibian (Weeks et al., 2002; Ohde et al., 2007) and Chilean (Gallardo and Espinoza, 2008) coastal waters in relation with high hydrogen sulphide ( $\mathrm{H}_{2} \mathrm{~S}$ ) concentrations. Until now, there is no data available to validate this hypothesis for Paracas Bay.

The growth (Tarazona et al., 2007; Thébault et al., 2008), reproduction (Illanes et al., 1985; Wolff, 1988; Cantillanez et al., 2005; Avendaño et al., 2008) and more widely population dynamics (Wolff, 1987; Mendo and Wolff, 2003; Cantillánez et al., 2007; Wolff et al., 2007) of the Peruvian scallop in both Peru and Chile have been studied mainly in the context of environmental variability related to ENSO. However, these warm events are sporadic while most production 
campaigns were conducted under "normal" conditions, which have been rarely investigated. Daily microgrowth studies have shown how environmental variability influences shell growth rates in $A$. purpuratus (Thébault et al., 2008; Aguirre-Velarde et al., 2015), suggesting the importance of improving our knowledge on the effect of environmental conditions on scallop productive performance. The present study was carried out to characterize the environmental dynamics in Paracas Bay at a fine temporal scale in order to better identify the variability encountered by the scallops in cultivation and its productive consequences. The data obtained will help identifying the particular environmental conditions that increase production risks (mass mortality and/or low yields). This knowledge is essential to define a proper management according to of the environmental cues and to ensure sustainability of the Peruvian scallop commercial farming in the studied area. In addition, this work is a contribution to the understanding of the dynamics of coastal bays in the context of the Peruvian upwelling and its impacts on benthic resources.

\section{Material and methods}

\subsection{Scallops collection and experimental site}

In late August 2012, two batches of 2500 wild scallops ranging between 60-70 mm (size group 1, mean $=66.8 \mathrm{~mm}, 95 \%$ confidence interval: $\mathrm{CI}= \pm 0.97 \mathrm{~mm})$ and $30-40 \mathrm{~mm}($ size group 2, mean $=$ $36.5 \mathrm{~mm}, \mathrm{CI}= \pm 1.2 \mathrm{~mm})$ shell height were collected at Lagunillas Bay $(7.3 \mathrm{~km}$ south of Paracas Bay, Fig. 1). Scallops were immediately transferred at Paracas Bay and placed in a 5-m depth aquaculture area with sandy-muddy bottom $\left(13^{\circ} 49^{\prime} 35^{\prime} \mathrm{S}, 76^{\circ} 17^{\prime} 43^{\prime}\right.$ W, Fig. 1; tidal range $\approx 1$ m). Individuals were acclimated on the bay's bottom without any cage for 10 days before the beginning of the experiment. A third batch of 1000 individuals ranging from 35 to $45 \mathrm{~mm}$ shell height (size group 3, mean $=41.5 \mathrm{~mm}, \mathrm{CI}= \pm 1.14 \mathrm{~mm}$ ) was collected in late December 2012 following the same procedure. The absence of recruitment in Paracas Bay during the study period explains the transfer of scallops from Lagunillas; this practice is frequently used by scallop farmers in this area.

Figure 1: Map of the experimental site in Paracas Bay (Peru; $13^{\circ} 49^{\prime} 35^{\prime \prime} \mathrm{S}, 76^{\circ} 17^{\prime} 43^{\prime \prime} \mathrm{W}$ ). The experimental site was located in a 5-m depth area dedicated to the commercial farming of Argopecten purpuratus. Scallops used in the experiment were collected off Lagunillas. 


\subsection{Scallops culture set-up}

After acclimatization, scallops of each batch were randomly placed in cylindrical cages made of plastic-coated metallic frame and monofilament mesh (diameter $=50 \mathrm{~cm}$, height $=20 \mathrm{~cm}$, mesh size $=30 \mathrm{~mm})$ with a density of 30 individuals per cage $\left(150\right.$ ind.$\left./ \mathrm{m}^{2}\right)$. For each batch, scallops were placed into two growing conditions: half of the cages (25 replicates for size groups 1 and 2, and 9 replicates for size group 3) were placed on the sea bottom, in contact with the sediment, and the other half were suspended in the water column at $2 \mathrm{~m}$ above the sediment. The experimental setup is shown in Fig. 2. The cages were cleaned once a month to control biofouling development. A weekly monitoring of these cultures was conducted during a 7-months period between August 28, 2012 and March 10, 2013. This period includes late winter (September), spring (October-December) and summer (January-March) in the Southern hemisphere.

Figure 2: Schematic representation of the experimental set-up for scallop culture and environmental monitoring installed at Paracas Bay showing: suspended and bottom cages for scallop culture (respectively A and B), monitoring sensors (C), sediment traps (D), current meters (E) and the frame supporting the equipments $(\mathrm{F})$.

\subsubsection{Growth and reproduction monitoring}

At the beginning of the experiment and then weekly ( \pm 2 days), the scallops were sampled by removing one cage in each size group and culture depth. Shell height of live scallops was measured at the nearest mm using a caliper. After dissection, the wet weight of gonads and somatic soft tissues was measured using a $0.01 \mathrm{~g}$ accuracy balance. For each sampled cage, average shell height and somatic and gonadic wet weights with corresponding CI were calculated. A local polynomial regression (Cleveland et al., 1992) was used to assess the temporal trends of height and weight growth.

Reproduction (gametogenesis/spawning) was assessed in simple thought estimation of the Gonadosomatic index (GSI). For each sample, GSI was calculated based on individual soft tissue wet weights as:

$$
G S I=\frac{W W_{\text {gonad }}}{W W_{\text {gonad }}+W W_{\text {somatic }}} \cdot 100
$$


where $W W_{\text {gonad }}$ is the gonad wet weight and $W W_{\text {somatic }}$ is the somatic soft tissues wet weight. Average GSI and confidence intervals of each sample were calculated.

\subsection{Environmental monitoring}

Seawater conditions were monitored at the same depths as scallop cultures: (1) bottom, water-sediment interface and (2) Suspended, $2 \mathrm{~m}$ above the sea-floor in the water column. For this purpose, data-loggers, probes and sampling equipments (Fig. 2) were fixed on a metallic frame placed on the bottom (Fig. 2 F) or put directly on the sea-floor (Fig. 2 E, D).

\subsubsection{Sea water physico-chemical and wind descriptors}

Autonomous data-loggers set at both monitoring depths (Fig. 2 C) allowed recording temperature (HOBO U22-001), salinity (HOBO U24-002-C) and oxygen saturation (RBR TDO) with an hourly frequency. In order to ensure the quality of measurements, oxygen and salinity probes were calibrated fortnightly. Current speed was estimated hourly using inclinometer current meters (Marchant et al., 2014) equipped with a three axes inclinometer data-logger (HOBO UA-004-64) placed at the two monitoring depths (Fig. 2 E). The calibration curve between current speed and inclination was set-up into a hydraulic-test flume at the Fluid Mechanics Laboratory of the Universidad Nacional Agraria La Molina (La Molina, Peru).

Since the circulation patterns in Paracas Bay are strongly influenced by the local winds (Quispe-Sánchez, 2007), wind speed and direction data recorded at Pisco airport (1344’42” S, 76 '13'13" W, at 11.3 Km NE of the study site) were examined. The positive meridional wind $(v+)$ was used as a proxy of the intensity of the upwelling-favourable wind.

Additionally, the occurrence an duration of milky-turquoise water discoloration events (locally known as "aguas blancas") in Paracas Bay were recorded daily when visually observed.

\subsubsection{Trophic resource descriptors}

At each culture depth, trophic resource was characterized by monitoring various food proxies. Phytoplanktonic cell determination and counting were realized weekly ( \pm 2 days) on 1-L water samples collected at each depth using a horizontal Niskin bottle, and preserved in dark plastic bottles with Lugol. In-situ chlorophyll- $a$ and turbidity were estimated using fluorescence and 
turbidity sensors (Trilux, Chelsea Technologies Group Ltd) fitted on autonomous digital data loggers (Anticyclone Systems AntiLog). These sensor-logger assemblies were placed at each monitoring depth for $48 \mathrm{~h}$ every week (Fig. 2 C). During deployment, chlorophyll- $a$ concentration and turbidity were recorded every hour. Cylindrical sediment traps (collection area $=0.0081 \mathrm{~m}^{2}$, length $=0.60 \mathrm{~m}$ ) were deployed to estimate vertical fluxes of particulate matter $(\mathrm{PM})$; one of the traps was placed in the water column and the other one was plugged into the sea-floor so that the trap apertures remained at the monitored depths (Fig. 2 D). The sedimented particulate matter was recovered weekly from both traps. Particulate organic and inorganic matter (POM and PIM, respectively) were quantified after drying $\left(48 \mathrm{~h}\right.$ at $\left.60^{\circ} \mathrm{C}\right)$ and calcining $\left(3 \mathrm{~h}\right.$ at $\left.500^{\circ} \mathrm{C}\right)$ the trapped material. Weights were measured using a $10^{-5} \mathrm{~g}$ precision analytical balance. Particulate organic carbon and nitrogen (POC and PON, respectively) were quantified in aliquots of the captured material using a C-H-N organic elemental analyser (FLASH 2000 from Thermo Scientific). Vertical fluxes for all PM descriptors were calculated using the following equation:

$$
V F_{x}=\frac{W_{x}}{A_{\text {trap }} \cdot t}
$$

where, $V F_{x}\left(\mathrm{~g}\right.$ or $\left.\mathrm{mg} \mathrm{m}^{-2} \mathrm{day}^{-1}\right)$ is the vertical flux of the PM descriptor $x, W_{x}(\mathrm{~g}$ or $\mathrm{mg})$ is the total weight of the PM descriptor $x$ captured in the sediment trap, $A_{\text {trap }}\left(\mathrm{m}^{2}\right)$ is the inlet area of the sediment trap and $t$ (days) is the duration of trap deployment in the experimental area.

The C:N ratio (calculated as POC:PON) and PIM:PM ratio were computed from the measured particulate matter descriptors.

\subsection{Data analysis}

\subsubsection{Environmental variables}

Hypoxic conditions. Continuous recording of oxygen saturation allowed computing the daily and total monitoring cumulated hours during which the scallops were exposed to saturations lower than their ability to regulate oxygen uptake, i.e. the oxygen critical point $\left(\mathrm{P}_{\mathrm{c}} \mathrm{O}_{2}\right)$, estimated to 24.4\% (Aguirre-Velarde et al., 2016). These indices represent the daily and global exposition to hypoxic conditions, respectively. A local polynomial regression (Cleveland et al., 1992) was used to assess hypoxic conditions trends. 
Stratification. The degree of water column mixing between the two culture depths was characterized by a stratification index calculated according to $\mathrm{Li}$ (2002) as:

$$
S I=\frac{\Delta_{\sigma}}{\Delta_{\text {depth }}}
$$

where, $\Delta_{\sigma}$ is the difference in seawater density between the two culture depths calculated from temperature and salinity values using the IES80 equation and $\Delta_{\text {depth }}=2 \mathrm{~m}$ is the depth difference between the two culture conditions.

Statistics. The comparison of scallops mean heights and somatic weights between treatments (culture depths) at the end of the monitoring was performed using a t-test after checking normality (Shapiro test). Because of the non-normal distribution of environmental descriptors, differences between seasons and the two culture conditions were tested using the non-parametric (Pairwise) Wilcoxon test for each descriptor. Correlations between environmental descriptors were tested by cross-correlation analysis allowing identify time-lag relationships between the variables.

\subsubsection{Environmental influence on growth, reproduction and survival}

Because biological sampling and environmental monitoring were performed at different times, data were linearly interpolated when it was necessary to achieve regular step time-series.

The analysis of the influence of environmental conditions on growth was performed after removing the ontogenic reduction of growth rate (Gulland and Hold, 1959) according to the procedure described in Aguirre-Velarde et al. (2015). For this purpose, a weight-based von Bertalanffy growth function (VBGF) was fitted to somatic growth records from size groups 1 and 2 of the bottom treatment (considered as a reference). Then, growth rates were calculated from reference VBGF for each time step. Due to the strong environmental disturbances recorded during summer (hypoxic conditions, see Fig. 3), the fits were performed with growth observations from the winter-spring period (2012/08/28 and 2012/12/01). Observed somatic growth rate deviations ( $E_{\text {Growth }}$ ) to VBGF expectations were computed for each culture condition according Aguirre-Velarde et al. (2015) as:

$$
E_{\text {Growth.t }}=\overline{G R}_{t}^{\text {obs }}-G R_{t}^{\text {calc.bottom }}
$$

where, $E_{\text {Growth.t }}\left(\mathrm{g} \mathrm{d}^{-1}\right)$ is the somatic growth rate deviation at time $t ; \overline{G R}_{t}^{\text {obs }}\left(\mathrm{g} \mathrm{d}^{-1}\right)$ is the 
interpolated average growth rate at time $t$; and $G R_{t}^{\text {calc.bottom }}\left(\mathrm{g} \mathrm{d}^{-1}\right)$ is the predicted bottom growth rate at time $t$ (from VBGF).

Gonadosomatic index temporal trend (GSI-trend) was evaluated at each culture condition using local regression models (Cleveland et al., 1992) in order to smooth the gametogenesis-spawning cycles and detect variations in reproductive activity. GSI-trend deviations $\left(E_{G S I}\right)$ from a GSI reference (winter-spring average) were calculated.

A principal component analysis (PCA) was used to describe the relationships between environmental descriptors (time dependence removed), as a function of culture condition, and the observed growth $\left(E_{\text {Growth }}\right)$, reproduction $\left(E_{G S I}\right)$ and survival of the Peruvian scallop.

\section{Results}

\subsection{Environmental dynamics}

\subsubsection{Physico-chemical conditions}

Physico-chemical conditions of bottom seawater and $2 \mathrm{~m}$ above were generally more stable between late winter and late spring (from August to November, Fig. 3). During summer, important and rapid environmental changes were observed in both bottom and suspended cultures. Although the difference was low $\left(<0.8^{\circ} \mathrm{C}\right.$ ), temperature was significantly higher in suspended culture than on the bottom (Wilcoxon test, $p<0.001$ ). The minimum and maximum temperatures recorded were $13.8^{\circ} \mathrm{C}$ on the bottom and $25.0^{\circ} \mathrm{C}$ in suspended culture, respectively. Temperature (Fig. 3 c) exhibited a decreasing pattern at the beginning of the monitoring period (from late August to November) and was highly variable during summer (from late December to March). During summer, dramatic variations of temperature (up to $\approx 10^{\circ} \mathrm{C}$ ) occurred (Fig. $3 \mathrm{c}$ ) and were inversely related to salinity variations (up to $\approx 2$ ). Highest temperature variation rate reached $\approx 1{ }^{\circ} \mathrm{C}$ per hour. It is interesting to highlight that the lowest temperatures observed during summer were similar to those found in winter-spring.

Figure 3: Environmental descriptors recorded in Paracas bay on the bottom and in suspended culture: past seven-day moving average of upwelling favorable winds (a), salinity (b), temperature (c), oxygen saturation (d) and stratification index (e). The arrows and vertical dashed lines indicate 
the occurrence of milky-turquoise water discolorations in the bay.

In spite of the low average difference in temperature between bottom and suspended cultures, strong stratification events lasting 3-4 days occurred during the summer: instantaneous difference up to $8^{\circ} \mathrm{C}$ were recorded between the bottom and suspended cultures.

Median dissolved oxygen saturation $\left(\mathrm{O}_{\text {sat }}\right)$ was remarkably low at both culture depths: $25.6 \%$ on the bottom and $39.4 \%$ in the suspended treatment (significant differences: Wilcoxon test, $p<0.001$ ). At both depths, seasonal average $\mathrm{O}_{\text {sat }}$ was higher in winter (Pairwise Wilcoxon test, $p<0.001)$. A decreasing trend in $\mathrm{O}_{\text {sat }}$ was observed during spring, with significantly lower average value in summer than in winter and spring (Pairwise Wilcoxon test, $p<0.001$ ). Between December and March, strong variations of $\mathrm{O}_{\text {sat }}$ were observed at both depths, $\mathrm{O}_{\text {sat }}$ varying from oversaturation to anoxia. During summer, regular events of severe hypoxia and anoxia were observed at both depths although they were more marked on the bottom. The longest events ( $>5$ consecutive days) of severe hypoxia and anoxia were recorded between January and March on the bottom, when low oxygen conditions coincided with low temperatures. February was the coldest month during the 2013 summer season and it also presented the lowest oxygen saturations during the monitoring period. In the bottom treatment, $\mathrm{O}_{\text {sat }}$ was more frequently below the $\mathrm{P}_{\mathrm{c}} \mathrm{O}_{2}$ of $A$. purpuratus than in suspended culture. Over the whole monitoring period, bottom scallops were exposed to $\mathrm{O}_{\text {sat }}$ below their $\mathrm{P}_{\mathrm{c}} \mathrm{O}_{2}$ for $48 \%$ of the time; this proportion was only $18 \%$ for the suspended scallops. In suspended culture, $\mathrm{O}_{\text {sat }}$ lower than $25 \%$ were observed only at temperatures lower than $17.5^{\circ} \mathrm{C}$, while these hypoxic conditions occurred at temperatures up to $20^{\circ} \mathrm{C}$ at the bottom. It should be noted that hypoxic/anoxic events were frequently concomitant with abrupt decreases in temperature and frequently associated with the occurrence of milky-turquoise water discolorations in the Bay. These discolorations were visually observed four times during the summer of 2013 on Jan-03, Jan-28, Feb-07 and Mar-04 (Fig 3, turquoise arrows and vertical dotted lines). The milky-turquoise water events lasted between 2 and 3 days starting on the south-east side of the Bay and then expanding northwards especially in the afternoon when the local wind increased.

Seasonal average of daily hours spent in hypoxic conditions was significantly lower in 
winter (Pairwise Wilcoxon test, $p<0.001$ ) than in spring (increase trend) and summer (maximal values). In suspended culture, a large number of consecutive days ( $>10)$ with $\mathrm{O}_{\text {sat }}$ above $24.4 \%$ $\left(\mathrm{P}_{\mathrm{c}} \mathrm{O}_{2}\right)$ was observed between late August and late October. An important increase in daily hours spent in hypoxic conditions was observed in early October at the bottom, while this increase was observed later (early November) in suspended culture. From late winter (December) to summer, hypoxic conditions lasting for 24 hours were observed in both culture conditions although they were more frequent at the bottom. During summer, up to four consecutive days under hypoxic conditions were observed on the bottom while the maximum duration recorded in the suspended treatment was two days. At both depths, most recurrent hypoxic conditions were observed in early March.

Figure 4: Hypoxic conditions, daily counting of hours with oxygen saturation below Argopecten purpuratus critical oxygen point for respiration (24.4\% estimated in Aguirre-Velarde et al., 2016), underwent by scallops on bottom and suspended cultures. Lines represent the trends of hypoxic conditions estimated from a local linear regression for each culture

During all the monitoring period, median oxygen saturation exhibited clear daily cycles (Fig. 5) with minimum oxygen saturation around 6:00 and maximum value around 15:00 at both depths. On the bottom, hourly median oxygen saturation did not exceed the $\mathrm{P}_{c} \mathrm{O}_{2}$ between 21:00 and 11:00, but it exceeded the $\mathrm{P}_{\mathrm{c}} \mathrm{O}_{2}$ the whole day long in suspended culture.

Figure 5: Hourly distribution of oxygen saturation registered on scallops bottom (a) and suspended (b) cultures. The grey horizontal line represents the critical oxygen point for Argopecten purpuratus (24.4\%, Aguirre-Velarde et al., 2016)

The wind component $v+$ moving average tended to increase from winter 2012 to summer 2013 (Fig. 3 a). A relaxation period of $v+$ was observed on mid-December (late spring) while higher mean wind speed values were recorded during summer .

Temperature, oxygen saturation and stratification time-series were inversely correlated ( $p<0.05$ ) to $v+$ (daily average) while a positive correlation (cross-correlation analysis, 
$p<0.05)$ was observed between salinity and $v+$ with a 1-day time-lag. In addition, oxygen saturation was inversely correlated $\left(\mathrm{CCF}_{\max }=-0.42, p<0.05\right)$ to the stratification index while hypoxic conditions were positively correlated $\left(\mathrm{CCF}_{\max }=0.44 p<0.05\right)$, with a 5-day time-lag.

\subsubsection{Trophic resource availability and quality}

Phytoplankton cell concentration show an increasing trend during the monitoring period (Fig. 6 a) but did not showed any significant difference between culture depths (Wilcoxon Test, $p>0.05$ ). Maximum cell concentrations were observed between January and February at both depths, reaching up to $8 x 10^{8}$ cells $\mathrm{L}^{-1}$ in suspended culture. By contrast, the minimum cell densities were recorded in early September. Chlorophyll- $a$ weekly averages were significantly higher near bottom than in suspended culture during the summer period (Wilcoxon test, $p<0.05$ ), but the average chlorophyll- $a$ concentration over the whole monitoring period was significantly higher in suspended culture than near bottom (Wilcoxon test, $p<0.05$ ). Vertical fluxes of POM and PON were not significantly different between culture conditions (Kruskal-Wallis Test, $p>0.05$ ) and remained relatively constant over the monitoring period. Only the POC flux was significantly higher on the bottom compared to the suspended condition (Wilcoxon test, $p<0.05$ ). The C:N ratio ranged from 4 to 9, while strong variations of the PIM:PTM ratio were observed (from 0.04 to 0.74) at both monitoring depths (Fig. 7). No significant differences of PM quality descriptors were identified amongst culture conditions (Wilcoxon Test, $p>0.05$ ). At both culture depths, turbidity was low at the beginning of the monitoring period and increased after mid-October. Median turbidity was 2.6 times higher (Wilcoxon test, $p<0.001$ ) on the bottom than in suspended culture (Fig. 7 a). A turbidity peak (ca. 10 NTU) was recorded on the bottom in late spring.

Figure 6: Trophic descriptors recorded in Paracas Bay on the bottom (red lines) and in suspended cultures (blue lines): cell density (a), 48-hour chlorophyll- $a$ mean with 95\% confidence intervals (b), vertical fluxes of particulate organic Matter (c), Carbon (d) and Nitrogen (e).

Figure 7: Trophic resource quality descriptors recorded in Paracas Bay near bottom (red lines) and in suspended culture (blue lines): 48-hour turbidity mean with 95\% confidence intervals (a), C:N 
ratio (b), and PIM:TPM ratio.

\subsection{Scallop culture}

\subsubsection{Growth and reproduction}

At the end of the monitoring period, scallop shell height and somatic weights were significantly higher (t-test, $p<0.001$ ) in suspended culture than on the bottom for all size groups (Fig. 8). During the whole monitoring, inter-individual variability of these variables within cages remained relatively low. Shell growth in suspended cultures was quite regular while it stopped (size group 1) or strongly decreased (size group 2) at the bottom from November-2012 to January 2013 (Fig. 8 a). Somatic weight losses were observed (Fig. 8 b) in late spring (bottom; group 1) and summer (bottom and suspended; groups 1 and 2). Scallops in group 1 were the most affected at both culture depths with weight losses up to $25 \%$ in suspended culture compared to $20 \%$ on the bottom. At the end of the monitoring period (early March), a recovery in somatic weights of size groups 1 and 2 was observed in suspended culture. In group 3, for which the monitoring begun in early summer, somatic growth was not significant on the bottom after two months (t-test, $p>0.05$ ). In contrast, somatic growth was observed in the suspended treatment of size group 3, although it ceased between the last week of January and the third week of February.

Figure 8: Results of the growth and reproduction monitoring. Evolution of mean shell height (a) and somatic wet weight (b) and gonado-somatic index (c) of the three size groups of scallops cultured in bottom (red line) and suspended (blue line). The arrows and vertical dashed lines indicate the occurrence of milky-turquoise water discolourations in Paracas bay. Bars indicate $95 \%$ confidence intervals.

Average Gonado-somatic indices (GSI) were significantly higher in suspended culture $(\operatorname{mean}=24.7 \%, \max =33.4 \%, \min =12.8 \%)$ than on the bottom. $($ mean $=18.2 \%, \max =27.3 \%$, $\min =9.2 \%$ ). Three marked GSI cycles were observed between late August and late November (winter-spring) in size groups 1 and 2 in suspended culture (Fig. 8 c). In scallops reared on the bottom, only two GSI cycles were observed between September and late October. These cycles, synchronous between the scallop batches, had approximately a 28-30 day period. During summer, after January, average GSI were significantly lower without distinguishable cycles in any scallop 
batch. The GSI of scallops in suspended culture (no data for bottom culture) re-increased during the last weeks of monitoring (March). In size group 3, only scallops in suspended culture showed a significant increase in GSI in January, followed by a drop synchronous with other size groups. By contrast, scallops reared on the bottom exhibited the lowest GSI values among all size groups without any distinguishable cycle.

The somatic weight losses and reproductive cycle alteration (significant GSI decreases) coincided with hypoxic/anoxic events and milky-turquoise water discolorations during summer.

\subsubsection{Survival}

An initial decrease of survival was observed during the first three weeks of the monitoring in scallops groups 1 and 2 (Fig. 9 a and b). Then, survival stabilized until late spring when an important mortality occurred in scallops from both conditions in size group 2. This mortality event, concomitant with the first episode of "aguas blancas", was also recorded for group 1 individuals grown on the bottom in contrast to group 1 individuals reared in suspended culture. Scallops reared on the bottom were the most affected in terms of mortality related with the occurrence of milky-turquoise water events: no survivors were found in cages on the bottom at the end of the survey, whatever the scallop size group. In suspended culture, the highest survival rate was found in size group 3 (100\%; Fig. 9 c) followed by group $1(77 \%)$ and finally by group 2 for which the cumulative mortality exceeded $50 \%$.

Figure 9: Survival of scallops size groups 1 (a), 2 (b), and 3 (c) in bottom and suspended cultures. The arrows and vertical dashed lines indicate the occurrence of milky-turquoise water discolourations in Paracas Bay.

\subsection{Environmental impacts on scallop growth and reproduction}

Table 1: Summary of differences/similarities in environmental descriptors between bottom and suspended scallop culture conditions (Wilcoxon rank tested, $\mathrm{H}_{1}:$ median $_{1}>$ median $_{0}$ ). Significant $(p<0.05)$ higher median conditions are indicated with a plus sign $(+)$. Highly significant differences $(p<0.001)$ are indicated with grey background. 


\begin{tabular}{|c|c|c|c|c|}
\hline & & & \multicolumn{2}{|c|}{ Culture condition } \\
\hline & \multicolumn{2}{|c|}{ Environmental descriptor } & Suspended & Bottom \\
\hline \multirow{4}{*}{ Physico-chemical } & & Temperature & + & \\
\hline & & Salinity & & + \\
\hline & & Oxygen saturation & + & \\
\hline & & Hypoxic conditions & & + \\
\hline \multirow{10}{*}{ Trophic resource } & \multirow{6}{*}{ Availability } & Cell density & & \\
\hline & & Chlorophyll-a & + & \\
\hline & & POM & & \\
\hline & & PIM & & \\
\hline & & POC & & + \\
\hline & & PON & & \\
\hline & \multirow{4}{*}{ Quality } & Turbidity & & + \\
\hline & & $\mathrm{C}: \mathrm{N}$ & & \\
\hline & & Chl:POC & + & \\
\hline & & PIM:TPM & & \\
\hline
\end{tabular}

Results of Wilcoxon rank test $\left(\mathrm{H}_{1}:\right.$ median $_{1}>$ median $\left._{0}\right)$ for each environmental descriptor indicating differences/similarities between bottom and suspended conditions are summarized in table 1 . The most significant differences between the two cultivation depths were caused by the physico-chemical descriptors and turbidity. Although environmental conditions seemed more homogeneous in trophic terms, the results showed a relatively higher concentration of chlorophyll-a in suspended culture compared to higher POC concentration in bottom culture. In order to summarize scallop growing conditions and identify environmental variables regulating growth, only descriptors exhibiting a significant difference between depths $(p<0.05)$ were used for PCA. The first and second principal components (Dim. 1 and 2) that explain 35\% and 24.9\% of the variance, respectively, are plotted in Fig. 10. Globally, physicochemical variables have a greater contribution to Dim. 1 and 2 than trophic variables. Although oxygen saturation makes an important contribution to Dim 1 (-0.96), clear negative correlations can be distinguished between hypoxic conditions, turbidity and milky-waters on one hand, and the response variables $E_{\text {Growth }}$, $E_{G S I}$ and survival on another hand. A correlation of -0.81 between hypoxic conditions and $E_{G S I}$ 
should be noted. Temperature and salinity are strongly correlated (-0.95); although their contribution to Dim 2 is important ( $>70 \%$ ), bottom and suspended groups can be distinguished more throughout Dim 1 than throughout Dim 2. In summary, the bottom group was mainly associated with "unfavorable conditions" (hypoxia and turbidity strongly correlated: 0.79) while the suspended one was linked to "favorable conditions" (oxygen saturation and temperature).

Figure 10: Principal component analysis performed on environmental characteristics of scallop culture treatments. Biplot representing the two first principal components where variables are T: temperature; Sat.O2: oxygen saturation; Sal: salinity; Hypox: Hypoxic conditions; Turb: turbidity; Chl: chlorophyll- $a$ and POC: Particulate Organic Carbon. Bottom culture is more related to hypoxic conditions and turbidity while suspended culture is associated with favorable oxygen saturation conditions.

\section{Discussion}

\subsection{Environmental variability}

The upwelling-influenced Peruvian coast is both a highly productive and dynamic ecosystem exhibiting remarkable temperature variations (Brink et al., 1983). The irregular alternation of warm (El Niño), neutral and cold (La Niña) periods known as El Niño Southern Oscillation (ENSO) causes an important environmental and oceanographic variability in this area. Although offshore large-scale temperature variability and winds patterns related to ENSO conditions are well documented (e.g. Burt et al., 1973; Pauly et al., 1989; Croquette, 2007), data on oceanographic dynamics inside Peruvian coastal bays are scarce. In Paracas Bay, Wolff (1987, 1988 ) reported $\approx 8-9^{\circ} \mathrm{C}$ temperature variations during the 1983-1984 El Niño and post-ENSO events. The same pattern was observed in northern Chile (Rinconada Bay, Thébault et al., 2008; Avendaño et al., 2017) which also supports a wind-driven upwelling system. Interestingly, this study emphasizes that strong variations in temperature (up to $8^{\circ} \mathrm{C}$ ) are frequently observed in Paracas Bay even under ENSO conditions considered as normal (reports 2012-2013; NOAA, 2013). Similar temperature range variation has been previously reported by Aguirre-Velarde et al. (2015) during a monitoring carried out between April and July 2007. The question of temperature variability in Paracas Bay was first addressed by Sears (1954), who hypothesized that the high 
temperatures were related to solar heating during a long upwelling relaxation period. High frequency data in this study show positive and negative temperature variations within the range of few hours suggesting that this variability is rather due to changes in water masses entering in the Bay. The correlation of temperature variations with the $v+$ wind component, as well as with other physico-chemical descriptors (salinity, dissolved oxygen and water column stratification), supports this hypothesis and emphasizes the importance of local winds on the hydrodynamics of this shallow bay. Although winds measured at the Pisco airport station might not be relevant at the scale of the Peruvian upwelling system, the meridional (v+) component could drive a local cold water vertical transport into the Bay. During summer, local southern wind is more intensive, while the offshore trade winds decrease and temperature increases (Pauly et al., 1989; Croquette, 2007; Gutiérrez et al., 2011). Local wind relaxation would allow the entrance of offshore warm water masses into the Bay. During winter, an active offshore upwelling (Bakun and Mendelssohn, 1989) would prompt more homogeneous conditions between the inshore and offshore areas thus explaining the more stable conditions observed at that time. Decoupling of in-offshore winds was already observed by Burt et al. (1973) on a daily scale but the inshore-offshore interactions/dynamics have been poorly studied.

Naturally highly productive coastal ecosystems, such as upwelling zones, are often characterized by low oxygen concentrations (e.g. Helly and Levin, 2004). This phenomenon is due to oxygen consumption in deep waters associated with the decomposition of the abundant organic matter originating from the superficial productive layer (Gewin, 2010; Zhang et al., 2010). The chronic and severe hypoxic/anoxic events observed in Paracas Bay are likely to be related to the local productivity-decomposition processes and the advection of oxygen-depleted deep water into the Bay. The last assumption is supported by the fact that severe hypoxic/anoxic events occur simultaneously with acute temperature decrease and salinity increase. Peruvian upwelled coastal waters are characterized by temperature and salinity in the ranges $14-18^{\circ} \mathrm{C}$ and $34.9-35.0$, respectively (Morón, 2000). As noted above, the wind probably drives hydrodynamics and therefore triggers hypoxic events in the Bay. Although low dissolved oxygen saturation was observed all along the monitoring period, the strongest hypoxic/anoxic events were observed in summer. Their occurrence would be related to higher local southerly winds relaxation $(v+)$ associated with higher primary production (phytoplankton cell density) and increased water column stratification. Such events might worsen the situation by limiting oxygenation of the 
bottom-water layer within the Bay. Similar summer increases of coastal hypoxia have been reported in Oregon (Gewin, 2010) and Benguela (Monteiro et al., 2008) upwelling systems.

In upwelling systems, the observation of milky-turquoise waters is generally associated with the presence of elemental sulphur micro-particles in seawater (Weeks et al., 2002, 2004; Ohde et al., 2007). These micro-particles originate from the oxidation of upwelled hydrogen sulphide $\left(\mathrm{H}_{2} \mathrm{~S}\right)$ produced in oxygen-depleted deep waters by anaerobic microbial metabolism (Millero et al., 1987). Although we did not measure either $\mathrm{H}_{2} \mathrm{~S}$ concentration or the presence of colloidal sulphur in the water, we can hypothesize that the occurrence of milky-turquoise waters, locally known as "aguas blancas" is due to this phenomenon. Indeed, water discolorations were observed only in cold and anoxic waters that would originate from oxygen-depleted and $\mathrm{H}_{2} \mathrm{~S}$ -enriched upwelled deep water after a strong water column stratification. Such events have been reported near Paracas Bay in 2009 (Schunck et al., 2013) and in the Hulmboldt (Arntz et al., 2006; Gallardo and Espinoza, 2008) and Benguela (Weeks et al., 2004; Ohde et al., 2007; Bruchert et al., 2009) upwelling systems. High productivity associated with higher stratification and likely greater local vertical transport (wind-driven) would increase the probability of occurrence of these events during summer. Sulphide toxicity was identified as the cause of mass mortality events in aquatic populations (see the review of Bagarinao, 1992).

\subsection{Impact of environmental forcing on bottom and suspended scallop cultures}

Most of the environmental measured descriptors exhibited similar patterns between bottom and suspended culture overall, except during strong summer stratification events. Nevertheless, although the depth difference between culture conditions was small, absolute values of the descriptors exhibited differences that might impact scallop bioenergetics. Apparently, the culture conditions differed more in terms of physico-chemical variables than in terms of food availability descriptors: oxic conditions and turbidity (both correlated) exhibited the strongest differences between bottom and suspended culture. Although the latter also faced hypoxic events, severe and continuous hypoxia was more pronounced at the bottom. These differences in exposure to hypoxia, in terms of intensity and duration, might induce differences in scallop physiology and energetics. Because high turbidity has been reported to affect bivalve pumping (Ellis et al., 2002) and clearance rates (Loosanoff, 1962; Ellis et al., 2002), it can also be hypothesized that higher 
turbidity the water-sediment interface might contribute to differences in scallop physiology and energetics between culture depths.

During the whole monitoring period and in both treatments, food availability estimated through Chl- $a$ concentration was relatively abundant (compared to oligotrophic coastal ecosystems) and may not be limiting in Paracas Bay, whatever the scallop culture depth. Average chlorophyll- $a$ concentration was higher in the suspended treatment than on the bottom however, no difference was found in terms of cell concentration. This pattern might be explained by higher irradiance leading to higher Chl- $a$ cell content $2 \mathrm{~m}$ off the bottom, depth-related differences in algal diversity, or more probably by an effect of fluorescence attenuation by turbidity levels near bottom (information provided by the sensor manufacturer). Higher mean POC flux together with higher turbidity in bottom water might be related to the deposition/resuspension of detritus and silt particules as shown by the PIM:TPM ratio. Strong PIM variability would be driven by terrigenous atmospheric inputs or resuspension due to strong wind events so-called "Paracas winds". Furthermore, the specific microalgal composition (phytoplankton, resuspended microphytobenthos), the potential occurrence of macroalgal detritus at both culture depths and other trophic descriptors such as the Chl-a:pheopigments ratio, the PIM:POM ratio, or the POC concentration would have to be considered to conclude on food resources and potential depth-related variations. In particular, the accumulation of PIM at the water-sediment interface induces an increase of the PIM:POM ratio near the seabed (see similar results in Thouzeau et al., 1991). Vahl (1980) and Wallace and Reinsnes (1985) have shown that such an increase inhibits nutrition and growth in Chlamys islandica above a PIM:POM ratio value of 3.5-4. Similarly, Thébault et al. (2008), under the assumption of daily shell growth rhythm, hypothesized that POC concentration would be stressful above $2.5 \mathrm{mg} \mathrm{L}^{-1}$ for Argopecten purpuratus in the Rinconada Bay.

\subsection{Consequences of hypoxic conditions on A. purpuratus}

In bivalves, growth variations have been often attributed to seston quantity and/or quality (Thouzeau et al., 1991; Grant, 1996; Lodeiros et al., 1996; Chauvaud et al., 1998; Lodeiros, 2000; Cantillánez et al., 2007; Hunauld et al., 2005; Lodeiros et al., 2011) to temperature and/or to the synodic month cycle (see Thébault et al., 2008, for review). In the Rinconada Bay (Chile), (Thébault et al., 2008) showed that water temperature, POC concentration and the lunar cycle (by 
synchronizing an endogenous oscillator) would regulate A. purpuratus shell growth. In Pacaras Bay, influenced by the nearby productive upwelling system, parameters such as oxic conditions and turbidity would also play a major role in scallop growth regulation (see PCA results in Fig. 10). The negative effect of hypoxia on growth has been reported in several aquatic species (Wu, 2002). Oxygen availability is susceptible to control bivalve bio-energetics and subsequently growth through various physiological/metabolic processes. Under hypoxic conditions, and beyond the oxyregulation ability, energetic yield is reduced due to the use of less efficient anaerobic pathways (Herreid, 1980; Pörtner and Grieshaber, 1993). Because metabolic costs of maintenance, including all processes that allow homeostasis, are covered in priority (Kooijman, 2010), reducing the energetic yield might impair allocation of energy to growth and reproduction. In addition, the accumulation of metabolic endproducts from anaerobic pathways may also modify the energy balance because of their toxicity (accumulation) and energy costs required for their elimination (Herreid, 1980). This hypothesis is in accordance with our observations: growth rate deviations were negatively related to hypoxic conditions. In addition, growth was lower on the bottom where exposure to hypoxia was twice higher than in suspended culture. Hypoxic conditions increased during summer in both treatments together with somatic weight loss, especially in large-sized scallop groups. Although the Peruvian scallop exhibits a high regulation ability for oxygen uptake (Aguirre-Velarde et al., 2016) and effective filtration and growth in oxygen-limiting conditions (Aguirre-Velarde et al., 2018), severe and chronic exposure to might have important bioenergetics implications if the energy available from assimilation for maintenance is insufficient. These assumptions were confirmed by simulation of the energy budget of A. purpuratus through a DEB model integrating the effect of hypoxia (see Aguirre-Velarde et al., 2019, , for details). Under such condition, energy mobilization from somatic tissues could occur and might explain the decrease of somatic weight observed in this study. However, in smaller size groups, for which oxygen diffusion might be more efficient due to a higher surface to volume ratio, weight loss was not observed. Surprisingly, shell growth (calcification) was maintained when weight loss was observed, may due to the low energetic cost of shell formation (Palmer, 1992).

The synchronous Gonado-somatic index cycles (gametogenesis and spawning phases) observed during winter and early spring appeared to have a monthly (close to 28 days) periodicity in both culture conditions. This pattern might be related to environmental variability due to the 29.5-day cycle describing the synodic month (Barber and Blake, 2006; Thébault et al., 2008) or to 
moon-related endogenous clocks (Takemura et al., 2010; Numata and Helm, 2015). In aquatic environments showing low variability of photoperiod and water temperature such as in tropical latitudes, moonlight intensity acts as a reliable zeitgeber that influences physiological activities (Takemura et al., 2010). To our knowledge, there is no previous study investigating the influence of the lunar phase on Peruvian scallop gametogenesis. Nevertheless, there are some reports of reproductive activity apparently related to lunar cycles in the Pectinidae family (Amirthalingam, 1928; Tang, 1941; Mason, 1958; Sastry, 1979; Parsons et al., 1992; Barber and Blake, 2006). This synchronism, observed during the first months of monitoring, was lost around November. The significant increase of hypoxic conditions at the bottom between October and November, and in both culture conditions during the summer, might have impacted scallop reproduction. As for growth, negative effects of hypoxia on reproduction of aquatic organisms have already been reported (Diaz and Rosenberg, 1995; Levin et al., 2009; Zhang et al., 2010; Kodama and Horiguchi, 2011). Oxygen limitation may impair reproduction thus compromising the gonadal development and GSI cycles. In addition, as for somatic weight decrease, the hypothesis of a mobilization of reproductive tissues to cover the maintenance costs cannot be excluded. Similarly, a reduction in energy allocation to reproduction has been documented in the gastropod Nassarius festivus under decreasing oxygen concentration (Cheung et al., 2008). The strong relationship found between oxic conditions and GSI variations in the present study would indicate that oxygen availability does affect the reproductive capacity of $A$. purpuratus.

The mortality observed during the first month of the survey might be due to the initial handling stress. During summer, when hypoxic/anoxic conditions became recurrent, scallop survival decreased dramatically. Although A. purpuratus is tolerant to oxygen-limiting conditions, prolonged and repeated exposures to severe hypoxia or anoxia may have negative consequences on its survivorship as in other marine organisms (Wu, 2002; Levin et al.. 2009). In this regard, lower survival of scallops cultivated on the bottom could result from the longer and higher exposure to severe hypoxia/anoxia (below $\mathrm{P}_{\mathrm{c}} \mathrm{O}_{2}$ ) compared with the suspended treatment. In addition, since the hypoxia/anoxia events occurred together with milky-turquoise waters we hypothesize that the combined effects of oxygen depletions and the presence of sulphide would increase the negative effects on scallop energy balance and subsequently on growth, reproduction and survival. Similar results were found by Vaquer-Sunyer and Duarte (2010), through a meta-analysis for benthic communities. Sulphide toxicity lies on the inhibition of the respiratory 
chain at the level of cytochrome $c$ oxidase (Nicholls and Kim, 1982). In order to better understand the consequences of the exposure to both stressors in the different life-stages further experiments are needed to clarify the size dependence of the resulting physiological effects/damages. Although the thermal tolerance limits of the Peruvian scallop were not reached (Urban, 1994), the high temperature variability observed during the summer could induce an additional stress (inability to acclimate) that increases the vulnerability of this species during hypoxic/anoxic events.

\subsection{Implications for sustainable management of scallop aquaculture in Paracas} Bay

The occurrence of scallop mass mortality events in Paracas Bay due to environmental disturbances currently threatens the profitability and even the durability of scallop aquaculture in the Bay despite low initial operation costs and high economic value of the production. This study provides a contribution to the understanding of the Bay environmental dynamics that can be directly applied to the sustainable management of scallop culture. First, the dramatic impact of hypoxic conditions and milky-turquoise waters on scallop survival during the summer and early autumn, lead us to advise an annual production planning that avoids these periods as much as possible, as it would decrease the probability of exposing cultures to adverse environmental conditions. Second, because suspended culture allows better growth, GSI values and survival rate, the technical and economic feasibility of off-bottom farming systems should be evaluated and suspended culture should be implemented whenever possible. The combination of both management options could help reducing the culture cycle duration, as well as the scallop mortality risk. In addition, the reduction of mass mortality in bottom cultures would decrease the environmental impact of aquaculture activities on the seabed and on the benthos of the Bay. Whether scallops in culture could be transferred in other coastal areas during hypoxic/anoxic events and episodes of "aguas blancas" should be also evaluated in terms of technical feasibility and production cost increase, in order to reduce mortality risk. These management options will increase scallop production costs and may not allow maintaining the economic profitability of aquaculture activities in the Bay. The same conclusion was made by Kluger et al. (2019) for scallop aquaculture in Sechura Bay, but for somewhat different reasons (lack of natural seed supply requiring scallop seed from hatcheries in addition to ENSO-related mortality). The latter study and the present work highlight the need of site-specific management strategies in Peru due to environmental specificity of the different 
coastal areas. Finally, further studies are needed to estimate the carrying capacity of Paracas Bay taking into account the seasonal variability in oxygen availability (limiting factor). Such an estimation will also contribute to a better management of aquaculture activities in this area.

\section{Conclusions}

This study emphasized the important environmental variability that a coastal bay may be facing, particularly in an upwelling system. Warm/cold and normoxic/hypoxic/anoxic conditions alternated very rapidly in Paracas Bay highlighting the importance of high frequency monitoring to better understand how coastal environmental dynamics influences the physiology of aquatic organisms including cultured species such as the Peruvian scallop. The scallop aquaculture area in Paracas Bay is exposed to chronic hypoxia and anoxic events frequently accompanied by milky-turquoise waters (locally known as "aguas blancas"). The latter would result from the presence of toxic $\mathrm{H}_{2} \mathrm{~S}$. The exposure to such conditions had negative effects on growth and reproduction of Argopecten purpuratus. In addition, the anoxic events observed during the summer greatly affected the survival of cultivated scallops, particularly in bottom culture. Interestingly, the high productivity of the upwelling system is counterbalanced by low oxygen availability overall and frequent severe hypoxia/anoxia conditions which threaten scallop aquaculture activities in the Bay. Studying the oceanographic dynamics of the area at fine spatial and temporal scales would be necessary to better understand and foresee the environmental dynamics in the coastal bays. In addition, ex situ studies that allow isolating the effect of low oxygen saturation on scallop physiology and metabolism would be useful to better understand the patterns observed in the wild for growth, reproduction and survival. At the same time, a multistressor approach for future experimental and modelling studies is recommended, because hypoxia does not occur solely, as shown by our data. The results obtained in this study will help characterizing hypoxia occurrence and impacts in productive environments such as upwelling-influenced coastal areas, and defining future management practices for aquaculture activities.

\section{Acknowledgements}

This study was conducted within the framework of the "PpR Desarrollo y ordenamiento de la 
Acuicultura". The authors thank the Facultad de Pesqueria (FAPE-UNALM) for allowing access to the biological station at Paracas Bay and using the boat UNA-V for monitoring. We thank Juan Alcazar and the aquaculture company ACUICULTORES PISCO for allowing us to install the monitoring and experimental site in their farming areas. This work was supported by IRD within the framework of the LMI DISCOH, by the LabexMER (ANR-10-LABX-19-01) and by the PICS BISCOT. This work received financial assistance from the International Foundation of Science (IFS), grant number A/5210-1.

\section{References}

Aguirre-Velarde, A., Flye-Sainte-Marie, J., Mendo, J., Jean, F., 2015. Sclerochronological records and daily microgrowth of the Peruvian scallop (Argopecten purpuratus, Lamarck, 1819) related to environmental conditions in Paracas Bay, Pisco, Peru. J. Sea Res. 99, 1-8.

Aguirre-Velarde, A., Jean, F., Thouzeau, G., Flye-Sainte-Marie, J., 2016. Effects of progressive hypoxia on oxygen uptake in juveniles of the Peruvian scallop, Argopecten purpuratus (Lamarck, 1819). Aquaculture 451, 385-389.

Aguirre-Velarde, A., Jean, F., Thouzeau, G., Flye-Sainte-Marie, J., 2018. Feeding behaviour and growth of the Peruvian scallop (Argopecten purpuratus) under daily cyclic hypoxia conditions. J. Sea Res. 131, 85-94.

Aguirre-Velarde, A., Pecquerie, L., Jean, F., Thouzeau, G., Flye-Sainte-Marie, J., 2019. Predicting the energy budget of the scallop Argopecten purpuratus in an oxygen-limiting environment. J. Sea Res. 143, 254-261.

Amirthalingam, C., 1928. On lunar periodicity in reproduction of Pecten opercularis near plymouth in 1927-28. J. Mar. Biol. 15 (02), 605-641.

Arntz, W. E., Gallardo, V. a., Gutiérrez, D., Isla, E., Levin, L. a., Mendo, J., Neira, C., Rowe, G. T., Tarazona, J., Wolff, M., 2006. El Niño and similar perturbation effects on the benthos of the Humboldt, California, and Benguela Current upwelling ecosystems. Adv. Geosci. 6, $243-265$.

Avendaño, M., Cantillánez, M., Le Pennec, M., Thouzeau, G., 2008. Reproductive and larval cycle of the scallop Argopecten purpuratus (Ostreoida: Pectinidae), during El Niño-La Niña events and normal weather conditions in Antofagasta, Chile. Rev. Biol. Trop. 56 (1), 
121-32.

Avendaño, M., Cantillánez, M., Thouzeau, G., 2017. Evidence of clandestine harvest and failure of conservation policies for Argopecten purpuratus in the Rinconada Marine Reserve (Chile). Aquatic Conserv.: Mar. Freshw. Ecosyst. 27 (3), 588-603.

Bagarinao, T., 1992. Sulfide as an environmental factor and toxicant: tolerance and adaptations in aquatic organisms. Aquat. Toxol. 24, 21-62.

Bakun, A., Field, D. B., Redondo-Rodriguez, A., Weeks, S. J., 2010. Greenhouse gas, upwelling-favorable winds, and the future of coastal ocean upwelling ecosystems. Glob. Chang. Biol. 16 (4), 1213-1228.

Bakun, A., Mendelssohn, R., 1989. Alongshore wind stress, 1953-1984: correction, reconciliation and update through 1986. In: Pauly, D., Muck, P., Mendo, J., Tsukayama, I. (Eds.), The Peruvian upwelling ecosystem: dynamics and interactions. Vol. 18. ICLARM Conference Proceedings, pp. 77-81.

Barber, B. J., Blake, N. J., 1983. Growth and reproduction of the Bay Scallop, Argopecten irradians (Lamarck) at its southern distribution limit. J. Exp. Mar. Bio. Ecol. 66, 247-256.

Barber, B. J., Blake, N. J., 2006. Chapter 6: Reproductive Physiology. In: Scallops: Biology, Ecology and Aquaculture. Vol. Volume 35. pp. 357-416.

Barber, R. T., Chávez, F. P., 1986. Ocean variability in relation to living resources during the 1982-83 el niño. Nature 319 (6051), 279.

Belmadani, A., Echevin, V., Codron, F., Takahashi, K., Junquas, C., 2014. What dynamics drive future wind scenarios for coastal upwelling off Peru and Chile? Clim. Dyn. 43 (7-8), 1893-1914.

Brink, K., Halpern, D., Huyer, a., Smith, R., 1983. The physical environment of the Peruvian upwelling system. Prog. Oceanogr. 12, 285-305.

Brüchert, V., Currie, B., Peard, K. R., 2009. Hydrogen sulphide and methane emissions on the central Namibian shelf. Prog. Oceanogr. 83 (1-4), 169-179.

Burt, W. V., Enfield, D. B., Smith, R. L., Crew, H., 1973. The surface wind over an upwelling area near Pisco, Peru. Boundary-Layer Meteoroly 3, 385-391.

Cabello, R., Tam, J., Jacinto, M. E., 2002. Procesos naturales y antropogénicos asociados al evento de mortalidad de conchas de abanico ocurrido en la baha de Paracas (Pisco, Perú) en junio del 2000. Rev. Peru. biol. 9 (2), 49-65. 
Cantillanez, M., Avendano, M., Thouzeau, G., Lepennec, M., 2005. Reproductive cycle of Argopecten purpuratus (Bivalvia: Pectinidae) in La Rinconada marine reserve (Antofagasta, Chile): Response to environmental effects of El Niño and La Niña. Aquaculture 246 (1-4), $181-195$.

Cantillánez, M., Thouzeau, G., Avendaño, M., 2007. Improving Argopecten purpuratus culture in northern Chile: Results from the study of larval and post-larval stages in relation to environmental forcing. Aquaculture 272, 423-443.

Chauvaud, L., Thouzeau, G., Paulet, Y.-M., 1998. Effects of environmental factors on the daily growth rate of Pecten maximus juveniles in the Bay of Brest (France). J. Exp. Mar. Bio. Ecol. 227 (1), 83-111.

Cheung, S. G., Chan, H. Y., Liu, C. C., Shin, P. K. S., 2008. Effect of prolonged hypoxia on food consumption, respiration, growth and reproduction in marine scavenging gastropod Nassarius festivus. Mar. Pollut. Bull. 57 (6-12), 280-286.

Cleveland, W. S., Grosse, E., Shyu, W. M., 1992. Local regression models. Statistical models in S, 309-376.

Crain, C. M., Kroeker, K., Halpern, B. S., 2008. Interactive and cumulative effects of multiple human stressors in marine systems. Ecol. Lett. 11 (12), 1304-1315.

Croquette, M., 2007. Contribution à l'étude de l'upwelling du Pérou Chili. Ph.D. thesis, Ecole doctorale « Sciences de l'univers, de l'environnement et de l'Espace », Université de Toulouse III.

Diaz, R. J., Rosenberg, R., 1995. Marine benthic hypoxia: a review of its ecological effect and the behavioural responses of benthic macrofauna. Oceanogr. Mar. Biol. 33, 245-303.

Ellis, J., Cummings, V., Hewitt, J., Thrush, S., Norkko, A., 2002. Determining effects of suspended sediment on condition of a suspension feeding bivalve (Atrina zelandica): Results of a survey, a laboratory experiment and a field transplant experiment. J. Exp. Mar. Bio. Ecol. 267 (2), 147-174.

Gallardo, V. A., Espinoza, C., 2008. The evolution of ocean color. Proc. SPIE 7097, 70970G-1. Gewin, V., 2010. Dead in the water. Nature 466 (August), 812-814.

Grant, J., 1996. The relationship of bioenergetics and the environment to the field growth of cultured bivalves. J. Exp. Mar. Bio. Ecol. 200 (1-2), 239-256.

Gray, J. S., Wu, R. S.-s., Or, Y. Y., 2002. Effects of hypoxia and organic enrichment on the coastal 
marine environment. Mar. Ecol. Prog. Ser. 238, 249-279.

Gulland, J. A., Hold, S. J., 1959. Estimation of growth parameters for data an unequal time intervals. J. Cons. Inter. Exp. Mer 25, 47-49.

Gutiérrez, D., Bouloubassi, I., Sifeddine, A., Purca, S., Goubanova, K., Graco, M., Field, D., Méjanelle, L., Velazco, F., Lorre, A., Salvatteci, R., Quispe, D., Vargas, G., Dewitte, B., Ortlieb, L., 2011. Coastal cooling and increased productivity in the main upwelling zone off Peru since the mid-twentieth century. Geophys. Res. Lett. 38 (7), n/a-n/a.

Guzmán, M., Chávez, J., Morón, O., Sánchez, S., Flores, G., mar 1997. Evaluación de la calidad del madio ambiente marino en la bahía de Pisco - Paracas, 22 a 24 mayo 1996. Informe Progresivo $\mathrm{N}^{\circ}$ 54, Instituto del Mar del Perú, 3-41.

Helly, J. J., Levin, L. A., 2004. Global distribution of naturally occurring marine hypoxia on continental margins. Deep Sea Res. I 51 (9), 1159-1168.

Herreid, C. F., 1980. Review hypoxia in invertebrates. Comp. Biochem. Physiol. 67A, 311-320.

Hunauld, P., Vélez, A., Jordan, N., Himmelman, J. H., Morales, F., Freites, L., Lodeiros, C. J., 2005. Contribution of food availability to the more rapid growth of the scallop, Euvola ziczac (Pteroida, Pectinidae) in bottom than in suspended culture. Rev. Biol. Trop. 53 (3-4), 455-61.

Illanes, J. E., Akaboshi, S., Uribe, E., 1985. Efectos de la temperatura en la reproducción del ostion del norte Chlamys (Argopecten) purpuratus en la bahía de Tongoy durante el fenomeno El Niño 1982-83. Invest. Pesq. 32, 167-173.

Jacinto, M. E., Martinez, C., Sanchez, S., Flores, G., Pizarro, L., apr 1996 a . Evaluación de la varazón y contaminación en la bahía de Paracas - Pisco. Informe Progresivo $N^{\circ}$ 29, Instituto del mar del Perú, 3-46.

Jacinto, M. E., Morón, O., Villanueva, P., Cabello, R., Guzmán-Roca, M., Mar 1996 b . Evaluación de la calidad del medio marino en la bahía Pisco-Paracas (Informe Progresivo 26). Informe Progresivo $N^{\circ}$ 26, Instituto del Mar del Perú, 3-33.

Kluger, L. C., Taylor, M. H., Wolff, M., Stotz, W., Mendo, J., 2019. From an open-access fishery to a regulated aquaculture business: the case of the most important latin american bay scallop (Argopecten purpuratus). Rev. Aquacult. 11 (1), 187-203.

Kodama, K., Horiguchi, T., 2011. Effects of hypoxia on benthic organisms in Tokyo Bay, Japan: a review. Mar. Pollut. Bull. 63 (5-12), 215-20. 
Kooijman, S. A. L. M., 2010. Dynamic Energy Budget theory for metabolic organisation - third edition, cambridge Edition. Cambridge University Press.

Levin, L., Ekau, W., a.J. Gooday, Jorissen, F., Middelburg, J., Naqvi, S., Neira, C., Rabalais, N., Zhang, J., 2009. Effects of natural and human-induced hypoxia on coastal benthos. Biogeosciences (6), 2063-2098.

Li, W. K. W., 2002. Macroecological patterns of phytoplankton in the northwestern North Atlantic Ocean. Nature 419 (September), 154-157.

Lodeiros, C. J., 2000. Identification of factors affecting growth and survival of the tropical scallop Euvola (Pecten) ziczac in the Golfo de Cariaco, Venezuela. Aquaculture 182 (1-2), 91-114.

Lodeiros, C. J., Fernandez, R. I., Bonmati, A., Himmelman, J. H., Chung, K. S., 1996. Relation of RNA/DNA ratios to growth for the scallop Euvola (Pecten) ziczac in suspended culture. Mar. Biol. 126 (2), 245-251.

Lodeiros, C. J., Freites, L., Nuñez, M., Vélez, A., Himelmman, J. H., 2011. Venezuela. In: Shumway, S. E., Parsons, G. J. (Eds.), Scallops: biology, ecology and aquaculture. Second edition. Elsevier, pp. 1315-1336.

Loosanoff, V., 1962. Effects of turbidity on some larval and adult bivalves.

Marchant, R., Stevens, T., Choukroun, S., Coombes, G., Santarossa, M., Whinney, J., Ridd, P., 2014. A buoyant tethered sphere for marine current estimation. IEEE J. Ocean. Eng. 39 (1), $2-9$.

Mason, J., 1958. A possible lunar periodicity in the breeding of the scallop, Pecten maximus (1.). J. Nat. Hist. 1 (9), 601-602.

Mendo, J., Wolff, M., 2003. El impacto de El Niño sobre la produccion de concha de abanico (Argopecten purpuratus) en bahia Independencia, Pisco, Peru. Ecol. Apl. 2 (1), 51-57.

Millero, F. J., Hubinger, S., Fernandez, M., Garnett, S., 1987. Oxidation of $\mathrm{H}_{2} \mathrm{~S}$ in seawater as a function of temperature, pH, and Ionic strength. Environ. Sci. Thecnol. 21 (5), 439-443.

Monteiro, P. M. S., van der Plas, a. K., Mélice, J. L., Florenchie, P., 2008. Interannual hypoxia variability in a coastal upwelling system: Ocean-shelf exchange, climate and ecosystem-state implications. Deep. Res. Part I Oceanogr. Res. Pap. 55, 435-450.

Morón, O., 2000. Características del ambiente marino frente a la costa peruana. Boletín del Instituto del Mar del Perú 19 (1-2), 179-204.

Nicholls, P., Kim, J.-K., 1982. Sulphide as an inhibitor and electron donor for the cytochrome c 
oxidase system. Can. J. Biochem. 60 (6), 613-623.

Ñiquen, M., Bouchon, M., 2004. Impact of el niño events on pelagic fisheries in peruvian waters. Deep sea research part II: topical studies in oceanography 51 (6-9), 563-574.

NOAA, 2013. El Niño theme page.

URL: http: //www.pmel.noaa.gov/tao/elnino/1997.html

Numata, H., Helm, B., 2015. Annual, lunar, and tidal clocks.

Ohde, T., Siegel, H., Reißmann, J., Gerth, M., 2007. Identification and investigation of sulphur plumes along the Namibian coast using the MERIS sensor. Cont. Shelf Res. 27 (6), $744-756$.

Palmer, A. R., 1992. Calcification in marine molluscs: how costly is it? Proc. Natl. Acad. Sci. U. S. A. 89 (4), 1379-1382.

Parsons, G., Robinson, S., Chandler, R., Davidson, L., Lanteigne, M., Dadswell, M., 1992. Intra-annual and long-term patterns in the reproductive cycle of giant scallops Placopecten magellanicus (Bivalvia: Pectinidae) from Passamaquoddy Bay, New Brunswick, Canada. Mar. Ecol. Prog. Ser. Oldendorf 80 (2), 203-214.

Paulmier, A., Ruiz-Pino, D., 2009. Oxygen minimum zones (OMZs) in the modern ocean. Progress in Oceanography 80 (3), 113-128.

Pauly, D., Muck, P., Mendo, J., Tsukayama, I., 1989. The peruvian upwelling ecosystem: dynamics and interactions.

Pörtner, H.-O., Grieshaber, M. K., 1993. Critical po 2 (s) in oxyconforming and oxyregulating animals gas exchange, metabolic rate and the mode of energy production. In: Bicudo, J. (Ed.), The vertebrate gas transport cascade adaptations to environment and mode of life, crc press Edition. Boca Raton FL, USA, pp. 330-357.

Quispe-Sánchez, J., 2007. Simulación de la hidrodinámica en la Bahía de Paracas, Pisco-Perú; utilizando forzantes físicos. Master's thesis, Universidad Nacional Mayor de San Marcos.

Rabalais, N. N., Turner, R. E., 2001. Coastal hypoxia: consequences for living resources and ecosystems. American Geophyical Union.

Sánchez, G., Córdova, J., Ledesma, J., oct 1997. Informe ambiental en la zona industrial pesquera de la bahía de Paracas, Pisco, Perú. 25 al 27 de abril 1997. Informe Progresivo $\mathrm{N}^{\circ}$ 67, Instituto del Mar del Peru, 3-19.

Sastry, A. N., 1979. Pelecypoda (excluding ostreidae). In: Giese, A. C., Pearse, J. S. (Eds.), 
Reproduction of marine invertebrates, vol. 5, academic press, new york Edition. pp. 113-292.

Schunck, H., Lavik, G., Desai, D. K., Grosskopf, T., Kalvelage, T., Loscher, C. R., Paulmier, a., Contreras, S., Siegel, H., Holtappels, M., Rosenstiel, P., Schilhabel, M. B., Graco, M., Schmitz, R. a., Kuypers, M. M., Laroche, J., 2013. Giant Hydrogen Sulfide Plume in the Oxygen Minimum Zone off Peru Supports Chemolithoautotrophy. PLoS One 8 (8), e68661. Sears, M., 1954. Notes on the Peruvian coastal current. 1. An introduction to the ecology of Pisco Bay. Deep Sea Res. 1, 141-169.

Solis Acosta, J., oct 2000. Nutrientes en la bahía de Paracas, Pisco, en marzo y abril 2000 (Informe Progresivo 131). Informe Progresivo $\mathrm{N}^{\circ}$ 131, Instituto del Mar del Perú, 17-28.

Solis Acosta, J., Inca, J., jun 2000. Características hidroquímicas en la bahía de Paracas, Pisco, a fines de la primavera 1999. Informe Progresivo $N^{\circ}$ 123, Instituto del Mar del Perú, 3-19.

Takemura, A., Rahman, M. S., Park, Y. J., 2010. External and internal controls of lunar-related reproductive rhythms in fishes. J. Fish Biol. 76 (1), 7-26.

Tang, S., 1941. The breeding of the scallop, Pecten maximus (L.), with a note on the growth rate. Proc. Liverpool Biol. Soc. 54, 9-28.

Tarazona, J., Espinoza, R., Sols, M., Arntz, W., 2007. Crecimiento y producción somática de la concha de abanico (Argopecten purpuratus) en Baha Independencia, Pisco (Perú) comparados entre eventos El Niño y La Niña. Rev. Biol. Mar. Oceanogr. 42 (3), 275 - 285.

Thébault, J., Thouzeau, G., Chauvaud, L., Cantillánez, M., Avendaño, M., 2008. Growth of Argopecten purpuratus (Mollusca : Bivalvia) on a natural bank in Northern Chile : sclerochronological record and environmental controls. Aquat. Living Resour. 21, 45-55.

Thouzeau, G., Robert, G., Smith, S., 1991. Spatial variability in distribution and growth of juvenile and adult sea scallops, Placopecten magellanicus (G.), on eastern Georges Bank (Northwest Atlantic). Mar. Ecol. Prog. Ser. 74 (2-3), 205-218.

Urban, H. J., 1994. Upper temperature tolerance of ten bivalve species off Peru and Chile related to El Niño. Mar. Ecol. Prog. Ser. 107, 139-145.

Vahl, O., 1980. Seasonal variations in seston and in the growth rate of the iceland scallops, Chlamys islandica (O. F. Müller) from Balsjord, $70^{\circ}$ N. J. exp. mar. biol. ecol. 48, 195-204. Vaquer-Sunyer, R., Duarte, C. M., 2010. Sulfide exposure accelerates hypoxia-driven mortality. Limnol. Oceanogr. 55 (3), 1075-1082. 
Wallace, J. C., Reinsnes, T. G., 1985. The significance of various environmental parameters for growth of the iceland scallop, Chlamys islandica (pectinidae), in hanging culture. Aquaculture 44 (3), 229-242.

Weeks, S. J., Currie, B., Bakun, A., 2002. Massive emissions of toxic gas in the Atlantic. Nature 415, 493-494.

Weeks, S. J., Currie, B., Bakun, A., Peard, K. R., 2004. Hydrogen sulphide eruptions in the Atlantic Ocean off southern Africa: implications of a new view based on SeaWiFS satellite imagery. Deep Sea Res. Part I Oceanogr. Res. Pap. 51 (2), 153-172.

Wolff, M., 1987. Population dynamics of the peruvian scallop Argopecten purpuratus during the El Niño phenomenon of 1983. Can. J. Fish. Aquat. Sci. 44, 1684-1691.

Wolff, M., 1988. Spawning and recruitment in the Peruvian scallop Argopecten purpuratus. Mar. Ecol. Prog. Ser. 42, 213-217.

Wolff, M., Taylor, M., Mendo, J., Yamashiro, C., 2007. A catch forecast model for the Peruvian scallop (Argopecten purpuratus) based on estimators of spawning stock and settlement rate. Ecol. Modell. 209 (2-4), 333-341.

Wu, R. S. S., 2002. Hypoxia: from molecular responses to ecosystem responses. Mar. Pollut. Bull. $45,35-45$.

Zhang, J., Gilbert, D., Gooday, A. J., Levin, L., Naqvi, S. W. A., Middelburg, J. J., Scranton, M., Ekau, W., Peña, A., B. Dewitte, B., Oguz, T., Monteiro, P. M. S., Urban, E., N., R. N., Ittekkot, V., Kemp, W. M., Ulloa, O., Elmgren, R., Escobar-Briones, E., Van der Plas, A. K., 2010. Natural and human-induced hypoxia and consequences for coastal areas: synthesis and future development. Biogeosciences 7, 1443-1467. 


\section{Highlights}

- High frequency environmental recording in Paracas bay (Peru) showed frequent and chronic hypoxic conditions.

- Exposure to severe hypoxia and related environmental conditions clearly affected scallop bioenergetics and subsequently growth and reproduction.

- Milky-turquoise waters events affect negatively survival of Peruvian scallop 
Figures

Fig. 1. Map of the experimental site in Paracas Bay (Peru; 13॰49'35" S, 76॰17'43" W). The experimental site was located in a 5-m depth area dedicated to the commercial farming of Argopecten purpuratus. Scallops used in the experiment were collected off Lagunillas.

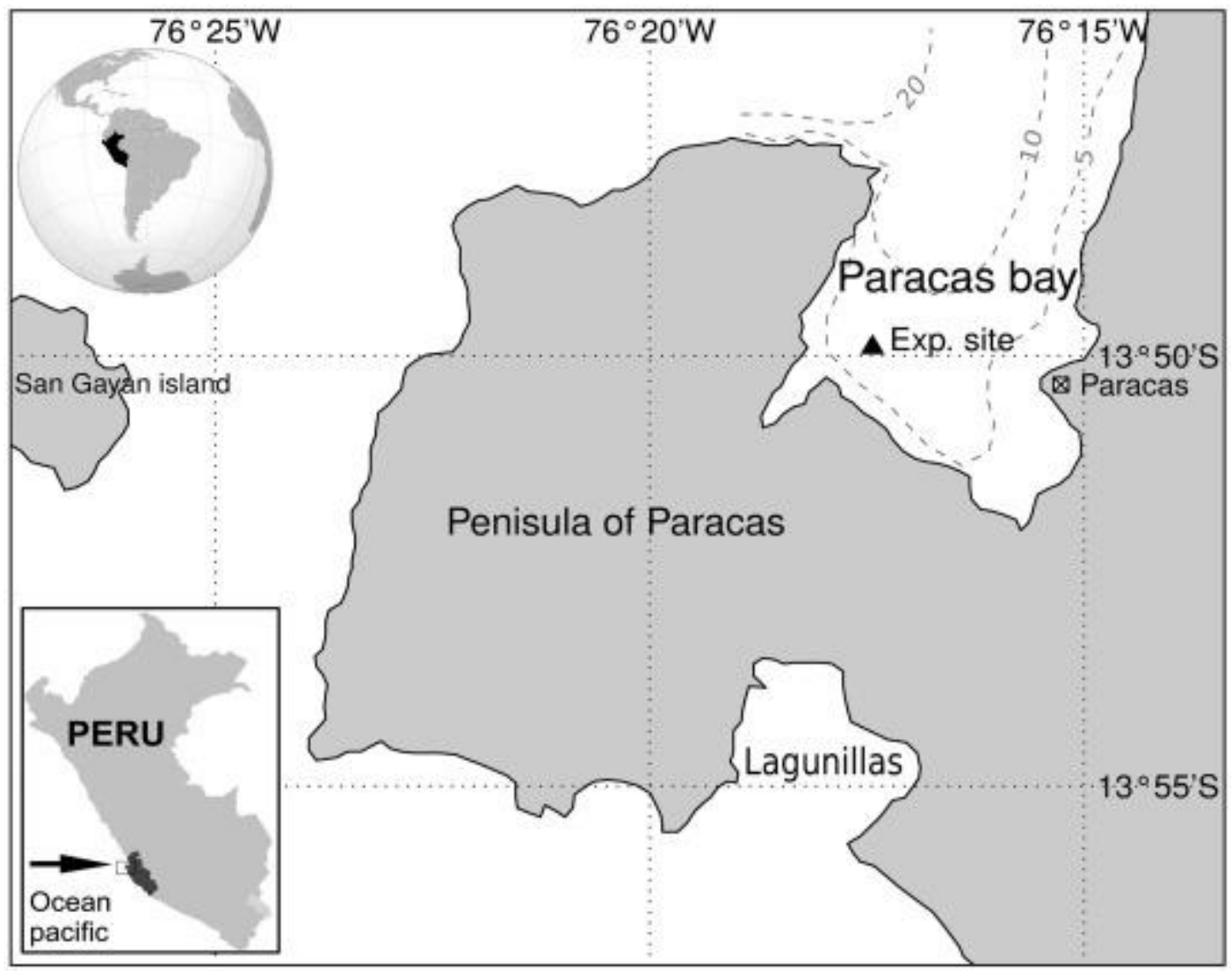

Fig. 2. Schematic representation of the experimental set-up for scallop culture and environmental monitoring installed at Paracas Bay showing: suspended and bottom cages for scallop culture (respectively $A$ and $B$ ), monitoring sensors (C), sediment traps (D), current meters $(E)$ and the frame supporting the equipments $(F)$.

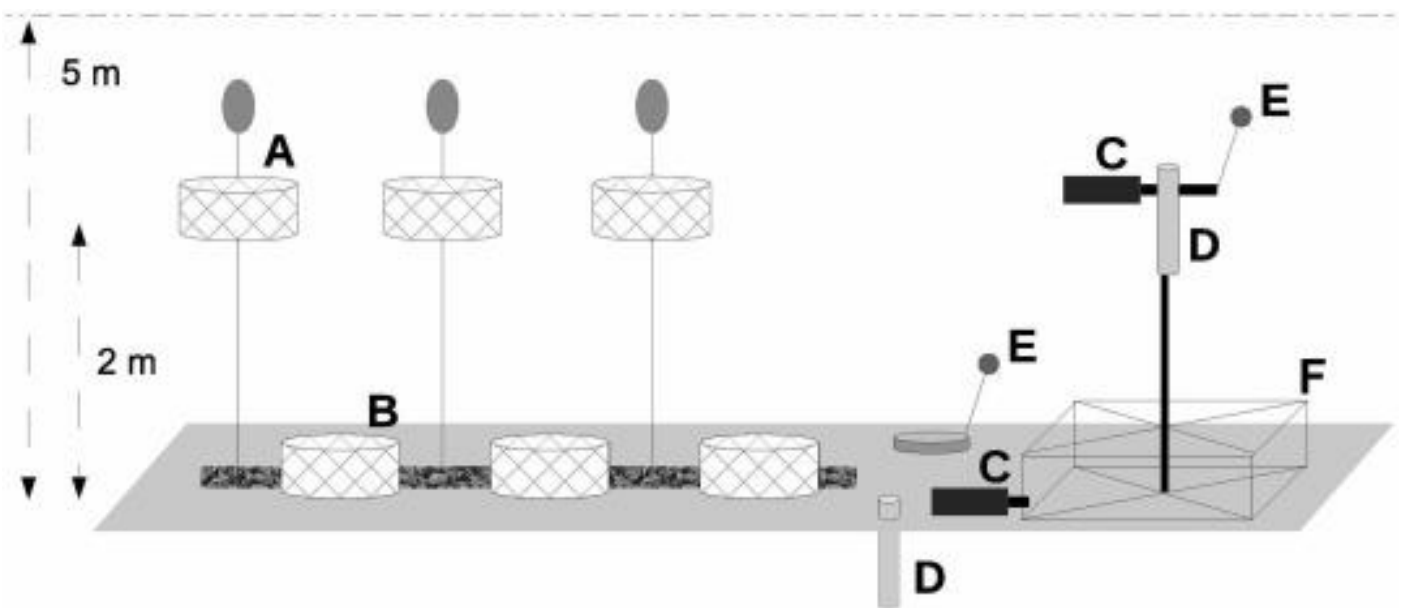


Fig. 3. Environmental descriptors recorded in Paracas bay on the bottom and in suspended culture: past seven-day moving average of upwelling favorable winds (a), salinity (b), temperature (c), oxygen saturation (d) and stratification index (e). The arrows and vertical dashed lines indicate the occurrence of milky-turquoise water discolorations in the bay. (For interpretation of the references to colour in this figure legend, the reader is referred to the web version of this article.)

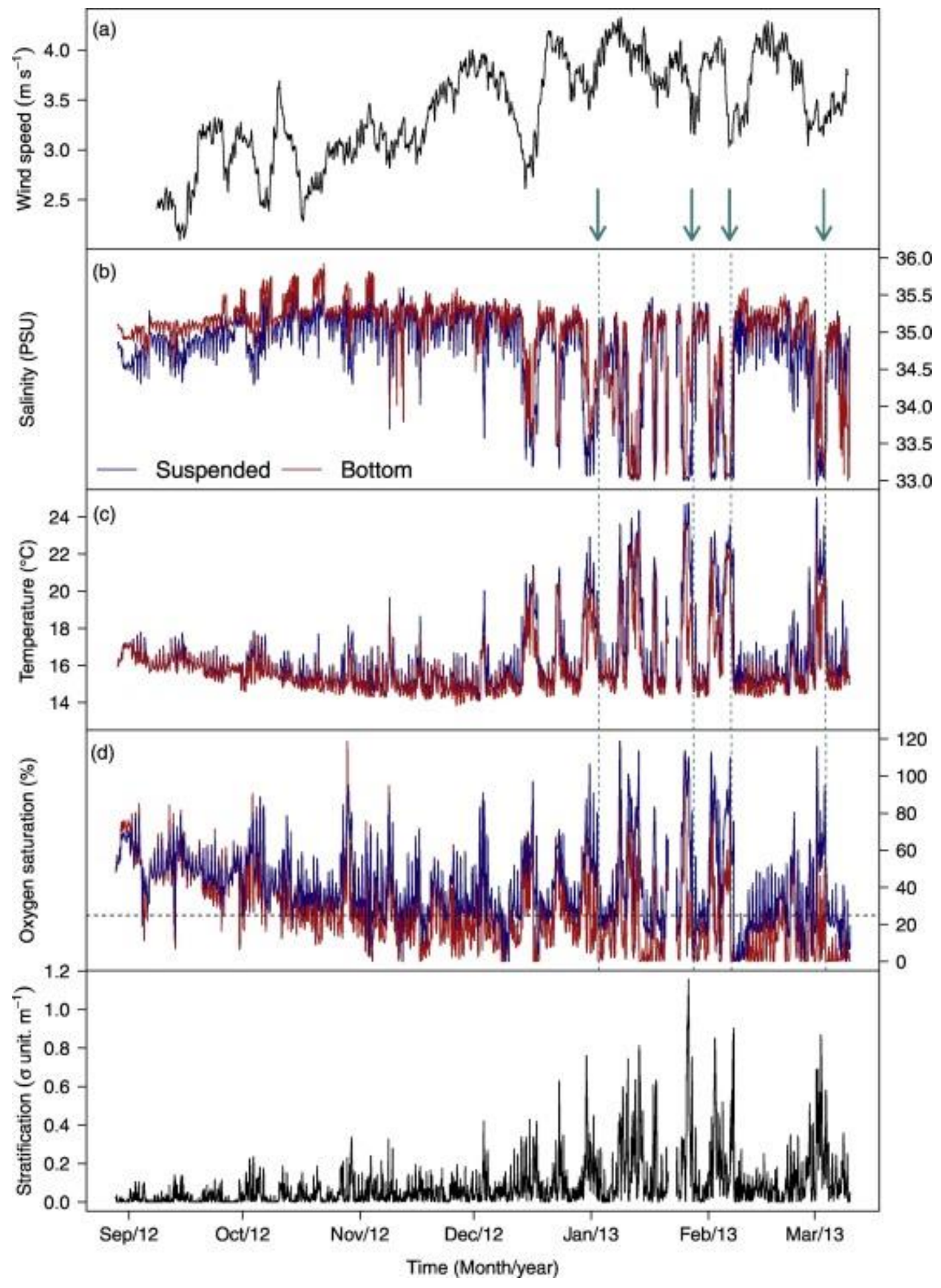


Fig. 4. Hypoxic conditions, daily counting of hours with oxygen saturation below Argopecten purpuratus critical oxygen point for respiration (24.4\% estimated in Aguirre-Velarde et al., 2016), underwent by scallops on bottom and suspended cultures. Lines represent the trends of hypoxic conditions estimated from a local linear regression for each culture.

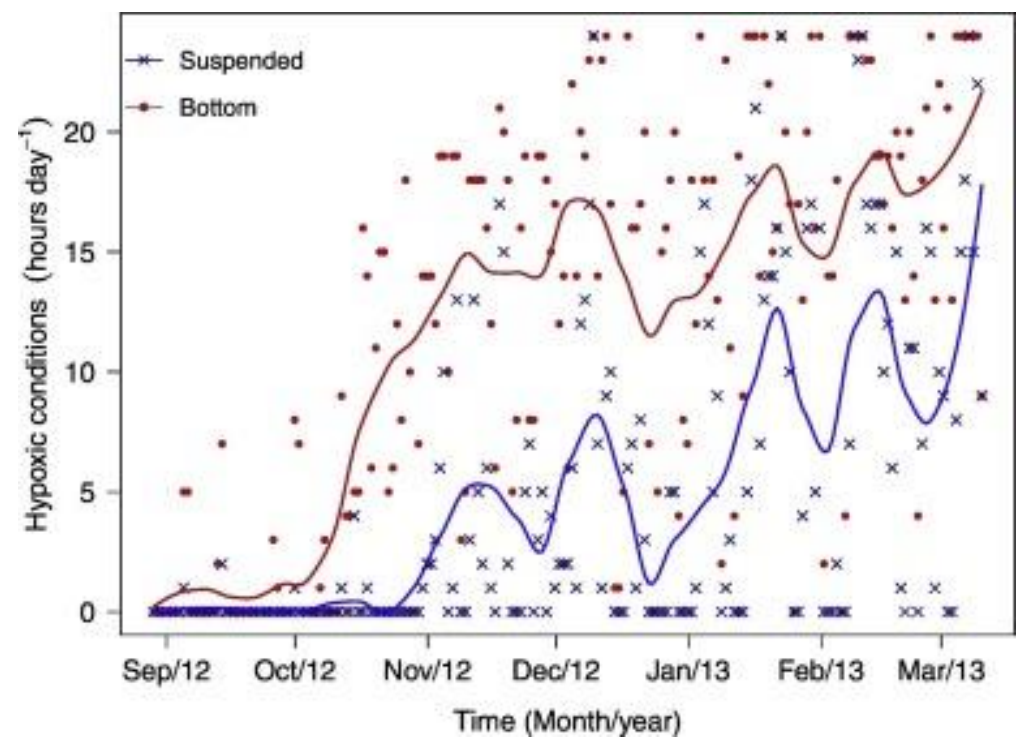

Fig. 5. Hourly distribution of oxygen saturation registered on scallops bottom (a) and suspended (b) cultures. The grey horizontal line represents the critical oxygen point for Argopecten purpuratus (24.4\%, Aguirre-Velarde et al., 2016).

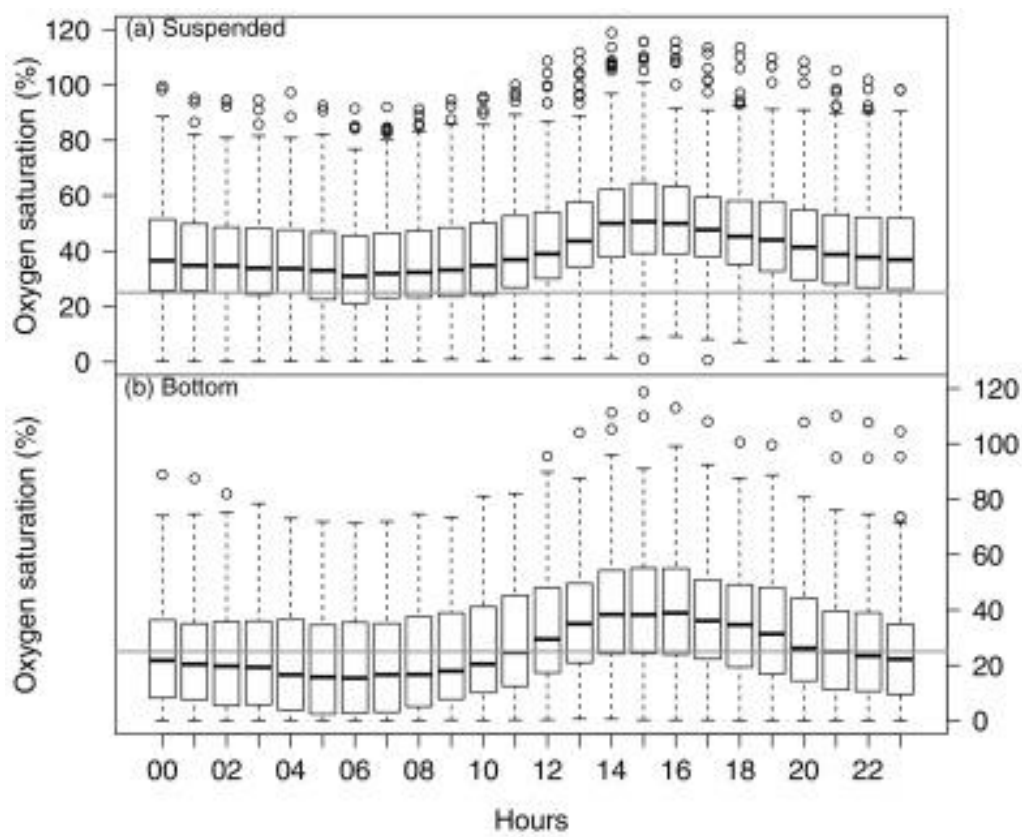


Fig. 6. Trophic descriptors recorded in Paracas Bay on the bottom (red lines) and in suspended cultures (blue lines): cell density (a), 48 -h chlorophyll-a mean with 95\% confidence intervals (b), vertical fluxes of particulate organic Matter (c), Carbon (d) and Nitrogen (e). (For interpretation of the references to colour in this figure legend, the reader is referred to the web version of this article.)

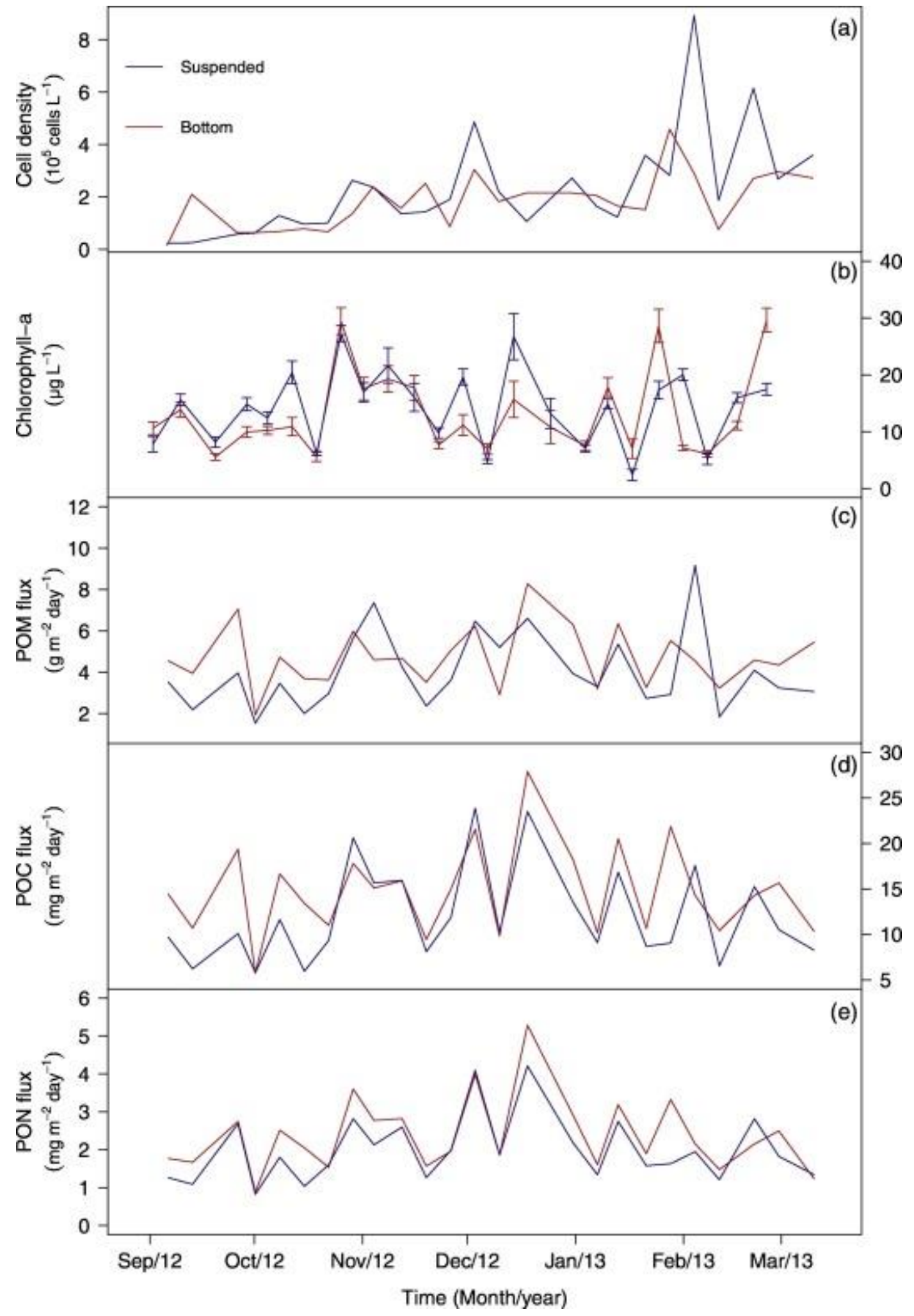


Fig. 7. Trophic resource quality descriptors recorded in Paracas Bay near bottom (red lines) and in suspended culture (blue lines): 48 -h turbidity mean with $95 \%$ confidence intervals (a), $\mathrm{C}: \mathrm{N}$ ratio (b), and PIM:TPM ratio. (For interpretation of the references to colour in this figure legend, the reader is referred to the web version of this article.)

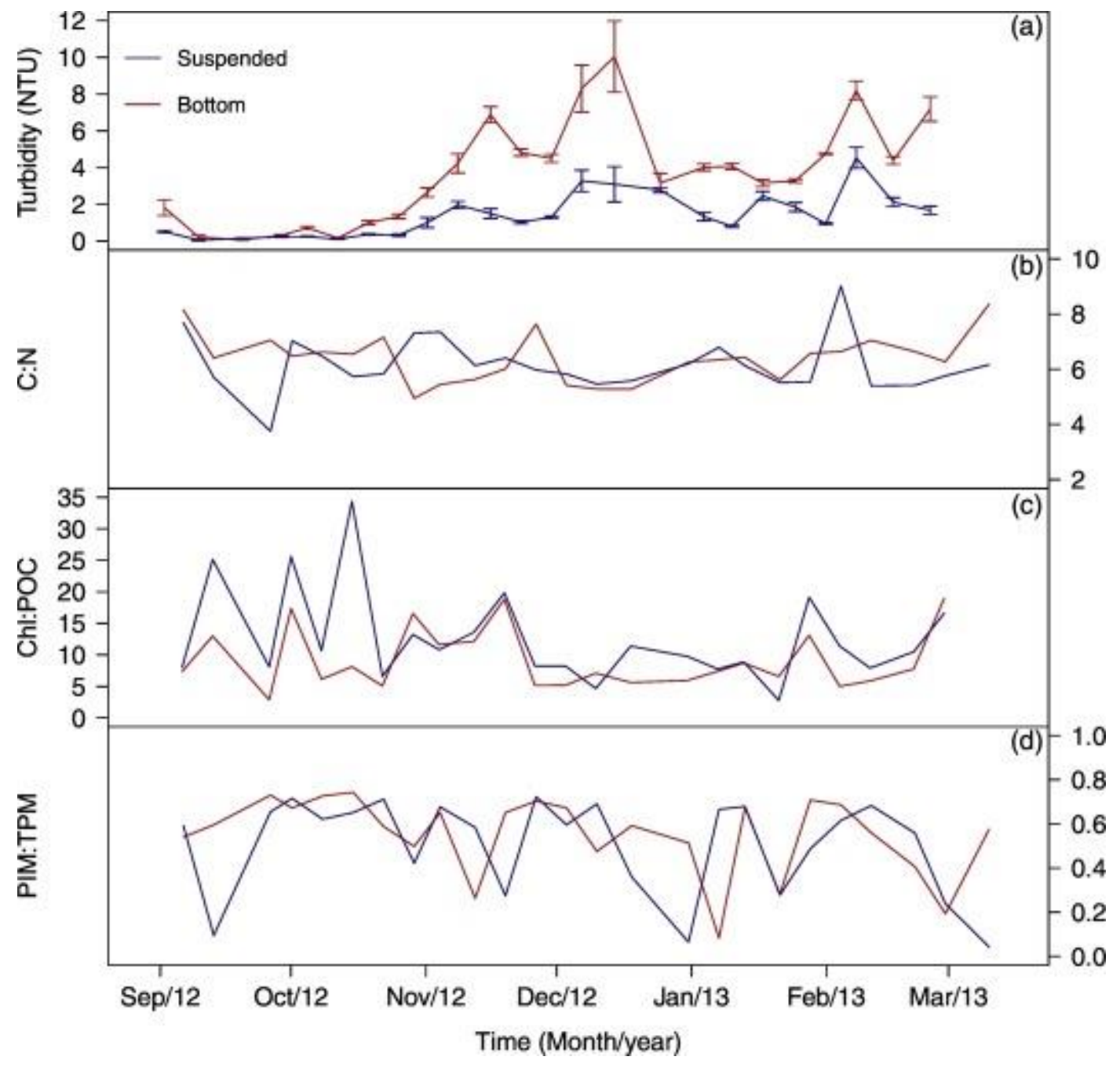


Fig. 8. Results of the growth and reproduction monitoring. Evolution of mean shell height (a) and somatic wet weight (b) and gonado-somatic index (c) of the three size groups of scallops cultured in bottom (red line) and suspended (blue line). The arrows and vertical dashed lines indicate the occurrence of milky-turquoise water discolourations in Paracas bay. Bars indicate $95 \%$ confidence intervals. (For interpretation of the references to colour in this figure legend, the reader is referred to the web version of this article.)

- Suspended - Bottom

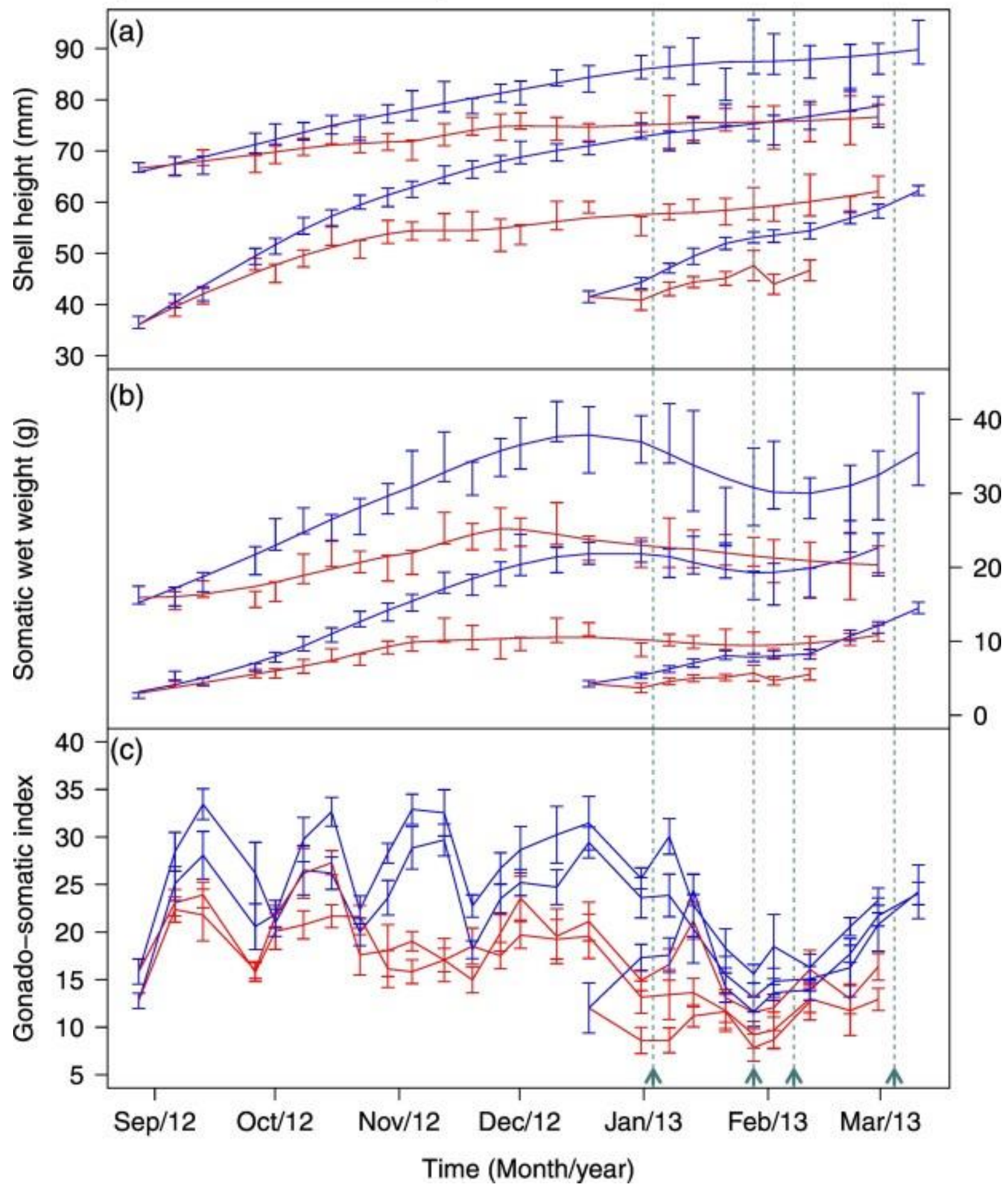


Fig. 9. Survival of scallops size groups 1 (a), 2 (b), and 3 (c) in bottom and suspended cultures. The arrows and vertical dashed lines indicate the occurrence of milky-turquoise water discolourations in Paracas Bay. (For interpretation of the references to colour in this figure legend, the reader is referred to the web version of this article.)

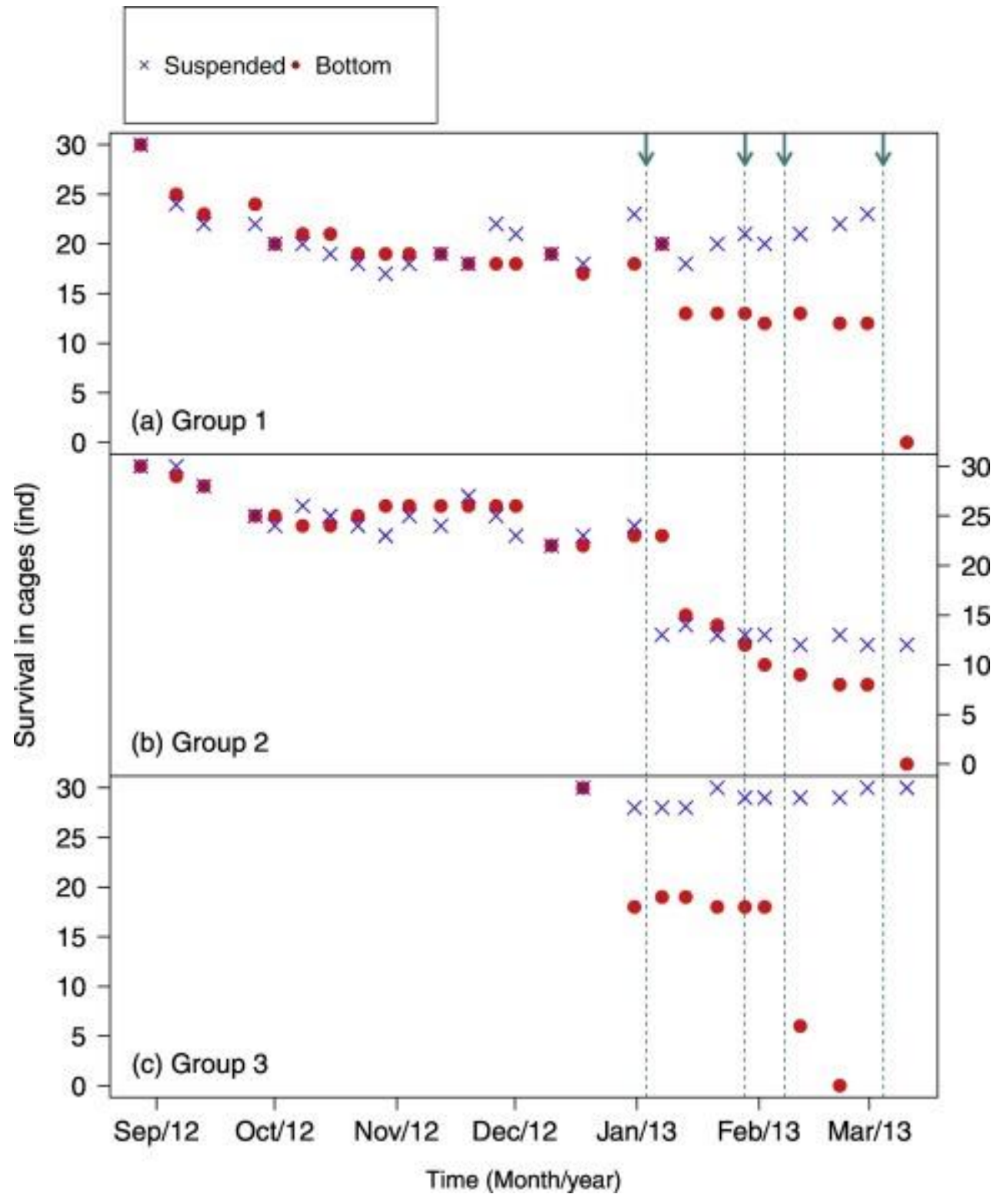


Fig. 10. Principal component analysis performed on environmental characteristics of scallop culture treatments. Biplot representing the two first principal components where variables are T: temperature; Sat.O2: oxygen saturation; Sal: salinity; Hypox: Hypoxic conditions; Turb: turbidity; Chl: chlorophyll-a and POC: Particulate Organic Carbon. Bottom culture is more related to hypoxic conditions and turbidity while suspended culture is associated with favorable oxygen saturation conditions.

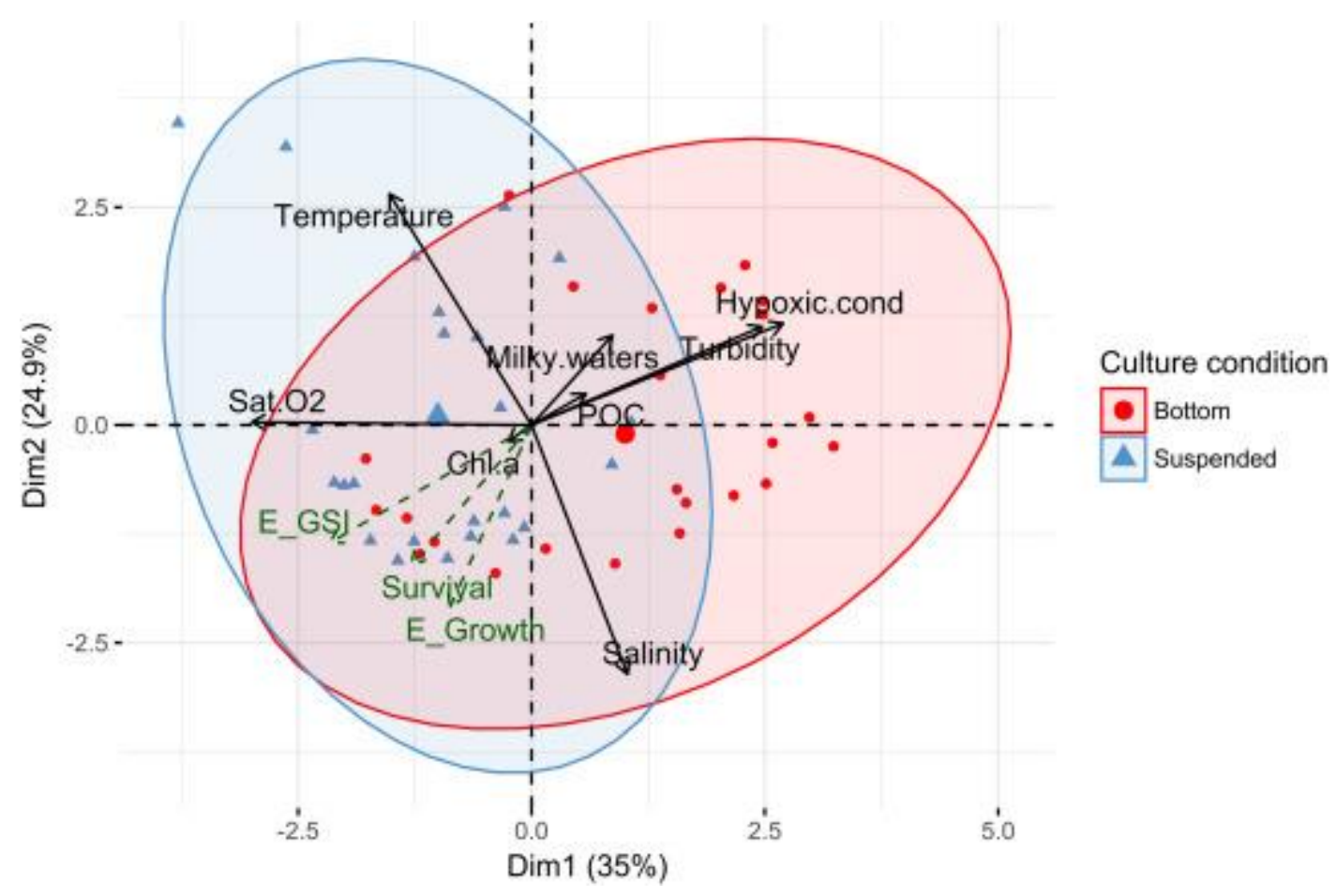

